\title{
Hydrogen plasma treatment of silicon thin-film structures and nanostructured layers
}

\author{
A.N. Nazarov ${ }^{1}$, V.S. Lysenko ${ }^{1}$, T.M. Nazarova ${ }^{2}$ \\ ${ }^{1}$ V. Lashkaryov Institute of Semiconductor Physics, National Academy of Sciences of Ukraine \\ ${ }^{2}$ National Technical University of Ukraine "KPI" \\ E-mail: nazarov@lab15.kiev.ua
}

\begin{abstract}
The review concentrates on the analysis of the RF hydrogen plasma effect on thin-film metal-dioxide-silicon and silicon-dioxide silicon structures which are a modern basis of micro- and nanoelectronics. The especial attention is paid to athermic mechanisms of transformation of defects in dioxide, $\mathrm{SiO}_{2}-\mathrm{Si}$ interface and $\mathrm{SiO}_{2}-\mathrm{Si}$ nanocrystal ones and thin layers of silicon; atomic hydrogen influence on the annealing of vacancy defects and the implanted impurity activation in a subsurface implanted silicon layer; and the hydrogen plasma effect on luminescent properties of nanostructured light emitting materials.
\end{abstract}

Keywords: silicon thin-film structures, hydrogen plasma treatment, nanostructured layer.

Manuscript received 22.04.08; accepted for publication 15.05.08; published online 30.07.08.

\section{Introduction}

The decrease of sizes of integrated circuit (IC) elements fabricated on the basis of a multilayer system such as the dielectric-semiconductor or semiconductor-dielectricsemiconductor ones leads to the necessity to research and to develop new technological methods. These methods have to allow one to create thin doped semiconductor layers without point and extended defects and the devices with small and controlled channel length and to reduce of the dispersion of electrical characteristics. Especially, it is related to the Si-based CMOS technology that is a basis of modern micro- and nanoelectronics. Nowadays, to diminish the diffusion redistribution of a dopant in the ion implanted regions of source and drain $p-n$ junctions or of the MOSFET channel, the low-temperature $\left(800-850{ }^{\circ} \mathrm{C}\right)$ thermal annealing or rapid thermal annealing (RTA) is used [1]. However, in some cases, the large mechanical stresses and structural defects can be produced. Additionally, the intensive development of nanotechnologies for the fabrication of nanostructured semiconductor materials and devices requires to create new methods to control the size and properties of nanocrystals incorporated in the semiconductor or insulator matrix and the nanocrystal/matrix interface.

The radio-frequency (RF) plasma treatment [2] is one of the unique methods for these cases. This method was employed in microelectronics from the time when the plasma-chemical technology began to be incorporated into the ICs fabrication. Nowadays, one of the kinds of this method (hydrogen plasma treatment) is employed for the fabrication of 3D ICs based on polysilicon films [3], for the solar cell production [4], and for thin-film transistor (TFT) fabrication in solid-state flat panel displays [5, 6].

Previously it was deemed that the effects of UV or $\mathrm{X}$-radiation and electron-ion bombardment (that accompanies the RF plasma treatment) are dangerous for the samples and have not to take part in the treatment [7]. However, as it will be shown latter, a correct choice of the treatment regime and the corresponding equipment for this goal could reveal the brilliant qualities of such an effect. These ones include: 1) annealing of positive charges in $\mathrm{SiO}_{2}[2,8]$ and surface state traps on the $\mathrm{SiO}_{2}-\mathrm{Si}$ interface [9] and the semiconductor nanocrystals / amorphous matrix interface [10-12]; 2) enhanced annealing and passivation of radiation defects in the thin subsurface silicon layer $[13,14]$; 3) activation of implanted dopants in this layer at low temperatures [15]; 4) formation of amorphous layers with fully structural relaxation of the amorphous network [16, 17].

The origin of the RF plasma annealing of the charge in the dielectric and subsurface semiconductor layer has been discussed in some papers [2, 18-20]. The main attention was devoted to the nonthermal processes of charge neutralization and charge annealing [20-22], especially this is referred to the processes of hydrogen passivation of defects and impurities in semiconductors $[22,23]$. In last years of the twentieth century, the considerable number of reviewed papers has been devoted to the hydrogen problem in crystalline semiconductors [23-30], and a number of significant 
international conferences included this question in their scientific programs [31-34]. But up today, there is no sufficiently full analysis of the physical processes running during the RF plasma treatment and leading to a considerable change of properties of the main micro- and nanoelectronics material which is the $\mathrm{SiO}_{2}-\mathrm{Si}$ system.

In this connection, the goal of this review consists in the consideration of the RF hydrogen plasma effect on electrical and structural properties of the main parts of the $\mathrm{SiO}_{2}$-Si system (silicon dioxide, $\mathrm{SiO}_{2}$-Si interface, and thin subsurface silicon layer) and in the analysis of various factors impacted this system. The main attention is spared to the nature of structural transformations of defects and the amorphous silicon layer during their interaction with atomic hydrogen under intense defect recharging. On the basis of this analysis, the prospects of applications of the hydrogen plasma annealing are considered.

\section{Factors influencing the structures under plasma treatment}

\subsection{Main kinds of plasma reactors}

Usually, in RF plasma treatments, the modified plasmaetching equipment is employed. Nowadays, two kinds of plasma reactors have a wide distribution: cylindrical quartz reactors with outer electrodes with capacitive (Fig. 1a) or inductive (Fig. 1b) coupling into gas [23]; parallel-plate type reactors with inner electrodes, in which a wafer is located between the grounded and RF electrodes (Fig. 2) [2, 14, 35].

In dependence on the goals of plasma treatment, a wafer can be located either directly in the plasma discharge (Fig. 2) or out of plasma (Fig. 1b). The last case is employed for the pure hydrogen passivation process and is used when all other effects except for hydrogenation are injurious. However, it is shown [36] that the simple system, which is depicted in Fig. 1b, possesses significant problems regarding to the UV radiation and energetic particle bombardment, and only the special design of a reactor allows one to reach pure hydrogenation.

\subsection{Factors affecting the samples in RF plasma discharge}

When it is necessary to perform a more effective treatment, the wafer is located on the RF electrode in a parallel-plate-type reactor (Fig. 2). In this case, the following factors can affect the sample: 1) ion and electron low-energetic bombardment; 2) ionizing X-ray or UV radiation; 3) alternating electric field; 4) thermal heating and hydrogen as an active gas contained in the plasma discharge.

Usually, the RF plasma treatment is performed when a frequency is $13.6 \mathrm{MHz}$, pressure is from $10^{-3}$ to $10^{-2}$ Torr, and power density is from 0.01 to $2.4 \mathrm{~W} / \mathrm{cm}^{2}$. The electric field amplitude can be reach $2 \times 10^{3} \mathrm{~V}$, and the treatment time is from 1 to $100 \mathrm{~min}$ in dependence on the power density $[3,18]$. a)
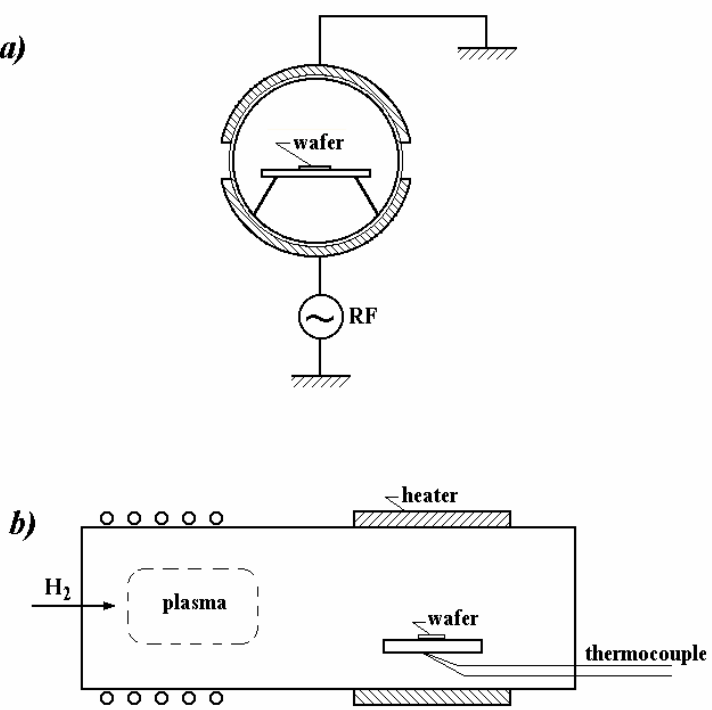

Fig. 1. Plasma-chemical reactors employed for the hydrogenation of a wafer with capacitive (a) and inductive (b) generation.

Let us consider the above-mentioned factors more attentively. Factors 1 and 2 are closely related to the frequency, the amplitude of the alternating electric field, and the pressure in a chamber. Indeed, because the electron and ion masses are considerably distinguished, the electron energy can considerably differ from the ion energy in dependence on the generator frequency. At the usually used gas pressure (near $10^{-2}$ Torr) and a standard frequency of the plasma treatment $(13.6 \mathrm{MHz})$, the electrons have time during a half-period of the signal to reach the electrodes with the energy which equals to the RF signal amplitude (in volts). The interaction of electrons with the electrodes leads to the appearance of soft $\mathrm{X}$-rays with energies corresponding to those of electrons. That is, electrons and $\mathrm{X}$-ray radiation in RF plasma discharges can reach energies up to $2 \times 10^{3} \mathrm{eV}$ [37].

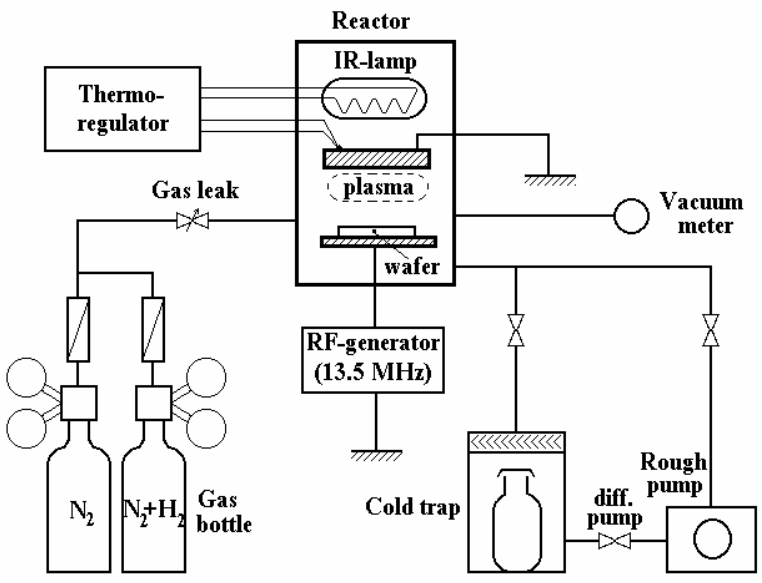

Fig. 2. Parallel-plate type reactor for RF plasma treatment. 


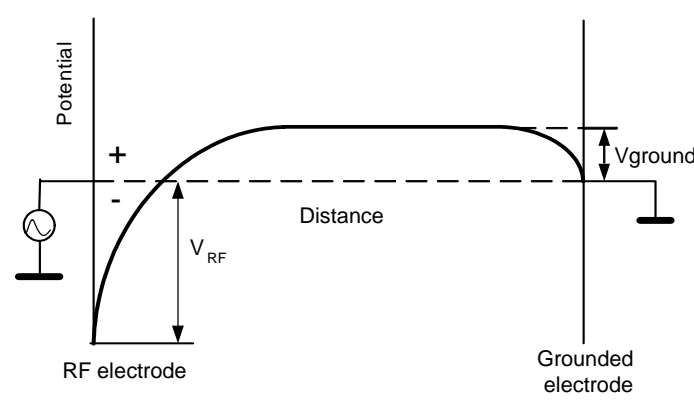

Fig. 3. Average potential distribution in a parallel-plate type reactor.

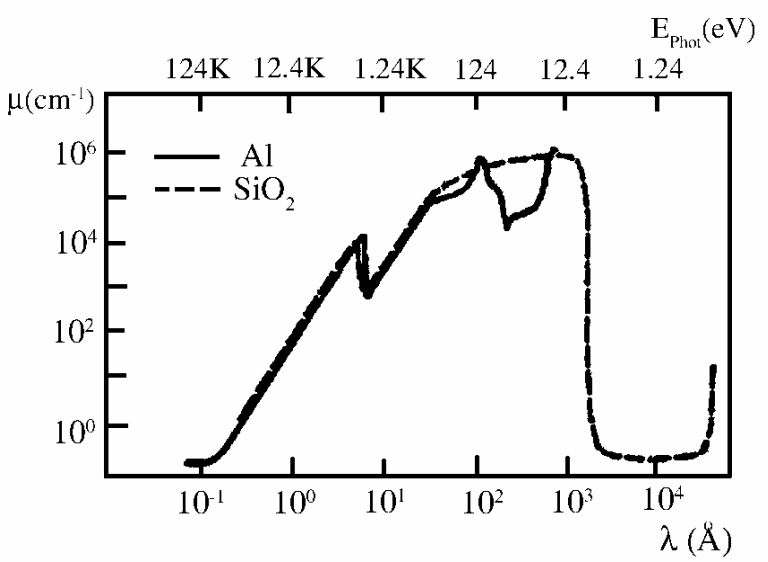

Fig. 4. Photon absorption coefficient for $\mathrm{Al}$ and $\mathrm{SiO}_{2}$ as a function of the photon energy [18].

Since the ions have not enough time for the motion from one to another electrode for a time of changing the signal polarity in the space between the electrodes, the specific distribution of the electrical potential has to be established (see Fig. 3) [38]. Thus, any surface incorporated into a RF plasma discharge has to be negatively charged relative to the ion cloud, and positively charged ions will bombard this surface. Usually, the energy of ions bombarding the samples located on a RF electrode does not exceed $200 \mathrm{eV}$ [37] and, in the case of a sample located on the grounded electrode, equals $2 \mathrm{eV}$ [39].

In most cases, the RF plasma treatment is used for the control over the properties of totally fabricated systems, i.e. metallized dielectric-semiconductor structures. Low-energy electrons and ions cannot penetrate through the metal electrode with thickness near $100-200 \mathrm{~nm}$. However, the photons with energies more than $100 \mathrm{eV}$ can penetrate through aluminum and the dielectric layer (Fig. 4) and reach the subsurface silicon layer.

Radiation and the alternating electric field can lead to the hole-electron injection from a semiconductor or a metal into a dielectric [18], which strongly affects the electrical and chemical processes running in the dielectric.

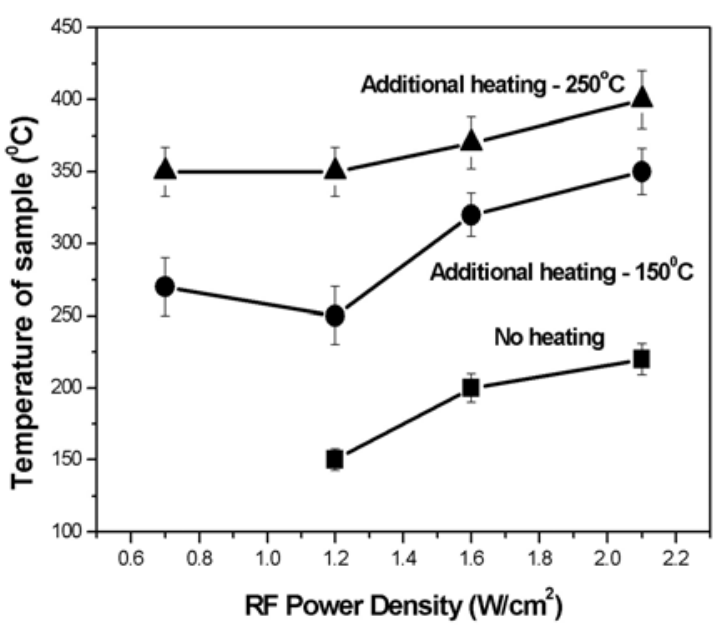

Fig. 5. Sample temperature vs. RF plasma power density for various conditions: without additional heating of the RF electrode (1), with additional heating up to $150{ }^{\circ} \mathrm{C}$ (2), and $250{ }^{\circ} \mathrm{C}(3)$. The circles and triangles are experimental points measured by calibrated thermally sensitive paints.

Ion and electron bombardments result in the heating of a wafer. The temperature of a sample is an important factor that determines the course of various chemical reactions running in the treated sample. The temperature is directly related to the RF treatment power, and it is controlled in dependence on the necessary result. The temperature of a sample located on the RF electrode in the parallel-plate-type reactor is presented in Fig. 5. It was measured with the use of special calibrated paints that change their color with variation in the temperature $[40,41]$. It is seen that the sample temperature does not exceed $450{ }^{\circ} \mathrm{C}$ at the most intensive plasma treatments.

\subsection{Hydrogen incorporation into $\mathrm{SiO}_{2}-\mathrm{Si}$ and $\mathrm{Si}_{-} \mathrm{SiO}_{2}-\mathrm{Si}$ structures under plasma treatment}

In papers [42, 43], it was established that the plasmachemical etching of $\mathrm{SiO}_{2}-\mathrm{Si}$ structures can lead to the atomic hydrogen permeation into the subsurface silicon layer. The similar effect has been observed after the RF plasma treatment of a structure in the nitrogen [44] and oxygen [39] atmospheres. In the case of a $\mathrm{SiO}_{2}-\mathrm{Si}$ structure treated by RF nitrogen plasma, the thermal hydrogen effusion spectrum from silicon exhibits a considerable increase of the signal at temperatures near and above $500{ }^{\circ} \mathrm{C}$ (Fig. 6) [20]. This evidences the creation of additional hydrogen bonds during the treatment. The breaking of Si-H bonds has been suggested to be responsible for this signal $[20,45]$.

Hydrogen penetrating into silicon has been suggested to be related to the presence of hydrogen in the outer gaseous atmosphere (as a residual moisture in the nitrogen atmosphere) and with hydrogen collected in $\mathrm{SiO}_{2}$ [20]. Nowadays, the direct measurements of the hydrogen concentration in $\mathrm{SiO}_{2}$ have been performed by the method of nuclear resonance reactions [46-48]. The hydrogen 
concentration is determined to be weakly dependent on the $\mathrm{SiO}_{2}$ fabrication method and is in the range from $1 \times 10^{19}$ to $4 \times 10^{21} \mathrm{~cm}^{-2}$ (see Fig. 7). The hydrogen concentration increases significantly after the deposition of a metal electrode (especially aluminum) on $\mathrm{SiO}_{2}$. In addition, the maximum hydrogen concentration is observed on the metal-dielectric interface. The following annealing in a forming gas at $450{ }^{\circ} \mathrm{C}$ increases the hydrogen concentration by a factor of more than 20 [47].

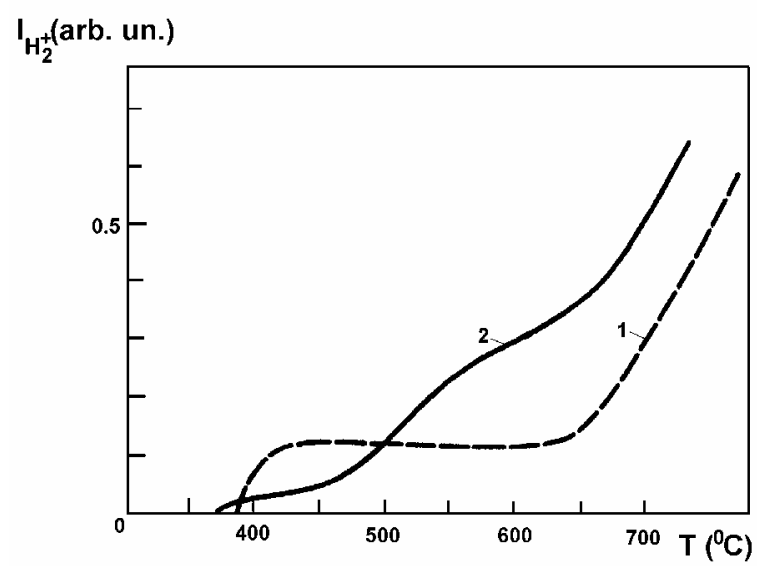

Fig. 6. Thermal desorption spectra of $\mathrm{H}_{2}^{+}$molecules from a silicon implanted layer after RF plasma treatment of $\mathrm{SiO}_{2}-\mathrm{Si}$ structures: 1 - initial structures (without treatment); 2 - after RF nitrogen plasma treatment; $\left(t=30 \mathrm{~min}, P=2.0 \mathrm{~W} / \mathrm{cm}^{2}\right.$, $T_{\text {heat }}=150^{\circ} \mathrm{C}$ ).
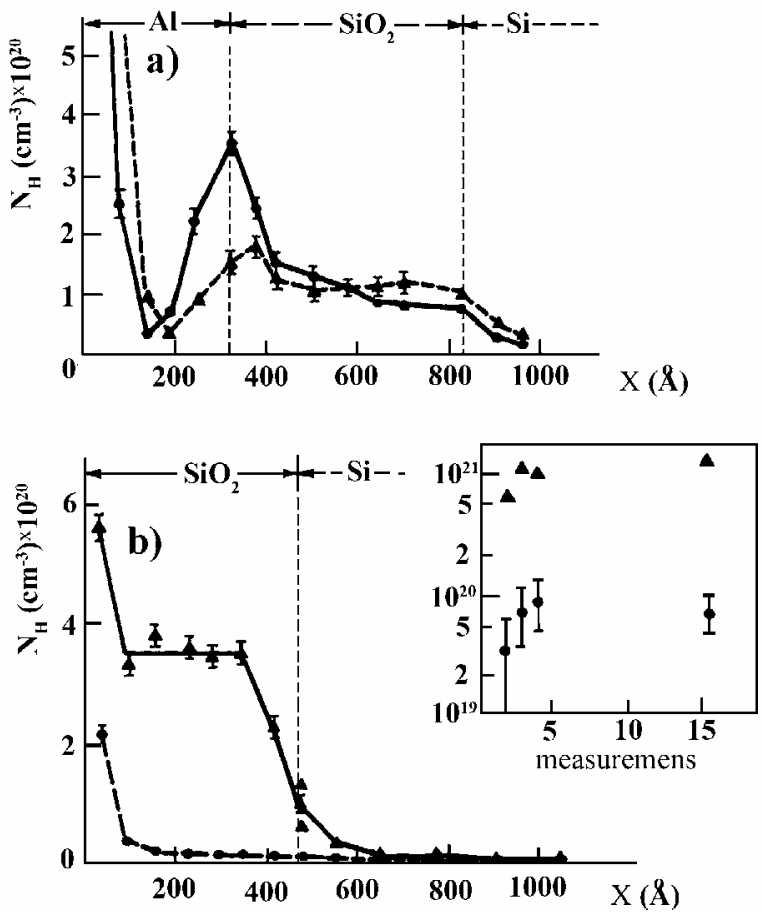

Fig. 7. Hydrogen distributions measured by the method of nuclear resonance reactions in (a) $\mathrm{Al}-\mathrm{SiO}_{2}-\mathrm{Si}$ structures fabricated by dry-wet-dry $(\bullet)$ and extra-dry oxidizing $(\boldsymbol{\Delta})$, and (b) $\mathrm{SiO}_{2}$-Si structures fabricated by dry oxidizing $(\bullet)$ and CVD (A) [47].

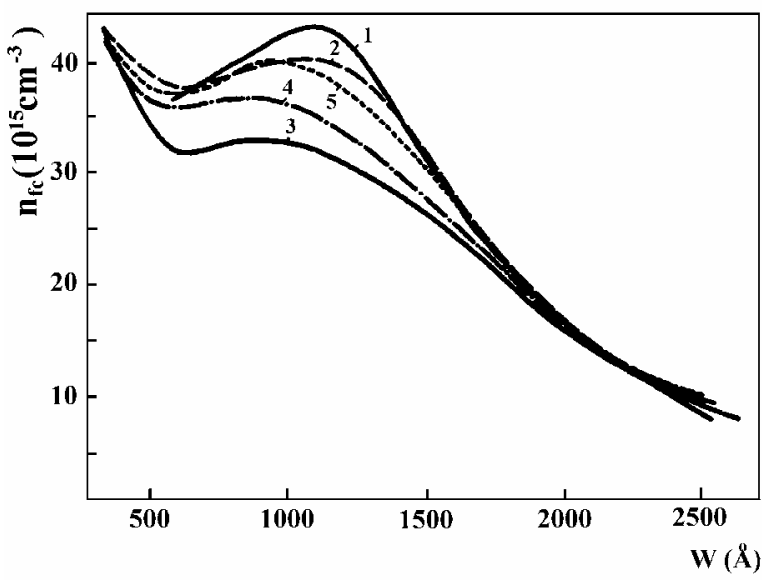

Fig. 8. Free carrier profiles in the subsurface silicon layer of Al- $-\mathrm{SiO}_{2}-p \mathrm{Si}$ structures $\left(\mathrm{B}^{+}\right.$implantation, $T_{\text {ann }}=1000^{\circ} \mathrm{C}$, $t=60 \mathrm{~min}$ ): 1) initial sample; 2) RF plasma treatment without additional heating $\left.\left(P=0.9 \mathrm{~W} / \mathrm{cm}^{2} ; t=30 \mathrm{~min}\right) ; 3\right)$ vacuum thermal annealing at $180^{\circ} \mathrm{C}$ during 30 min following the $\mathrm{RF}$ plasma treatment (30 $\mathrm{min})$; 4) vacuum thermal annealing at $200{ }^{\circ} \mathrm{C}$ during $30 \mathrm{~min}$ following the $\mathrm{RF}$ plasma treatment (30 $\mathrm{min})$ [44].

The hydrogen bond concentration in $\mathrm{SiO}_{2}$ has been determined by IR spectroscopy [49]. The concentrations of $\mathrm{Si}-\mathrm{H}$ and $\mathrm{Si}-\mathrm{OH}$ bonds in dry thermal oxide were near $1 \times 10^{20} \mathrm{~cm}^{-3}$, and they were considerably lower (near $3 \times 10^{19} \mathrm{~cm}^{-3}$ ) in the stream thermal oxide.

If X-rays (or UV irradiation) affect the $\mathrm{Al}-\mathrm{SiO}_{2}-\mathrm{Si}$ structure, to which the electric field is applied (factors that affects the structure during the RF plasma treatment), such joint effect has been shown to lead to the electron and hole injection into a dielectric [18]. The injected carriers, in their turn, promote the breaking of $\mathrm{Si}-\mathrm{H}$ and $\mathrm{Si}-\mathrm{OH}$ bonds and the release of hydrogen which will diffuse towards the $\mathrm{SiO}_{2}-\mathrm{Si}$ interface [50]. During the carrier injection into $\mathrm{SiO}_{2}$ (as it has been established in works [51-53]), the released atomic hydrogen is incorporated into the subsurface silicon layer and passivates the dopants.

The similar results have been obtained for the Al$\mathrm{SiO}_{2}-\mathrm{Si}$ structures treated by the RF forming gas $(10 \%$ $\mathrm{H}_{2}, 90 \% \mathrm{~N}_{2}$ ) plasma at a low specific power and without the additional heating of a sample [38]. As seen from Fig. 8, such RF plasma treatment leads to the neutralization of the electrical activity of boron in the subsurface silicon layer. The following thermal annealing in vacuum at $200{ }^{\circ} \mathrm{C}$ restores its electrical activity, which totally corresponds to the creation and to the destruction of the electrically neutral $\mathrm{Si}=\mathrm{B}-\mathrm{H}-\mathrm{Si}$ complex [23] and supports the suggestion about the diffusion of atomic hydrogen or protons from/through dioxide into the silicon substrate. Thus, silicon dioxide plays an essential role in the hydrogenation of the $\mathrm{SiO}_{2}-$ Si interface and the Si subsurface layer.

In a number of works [54-56] with the use of the method of Secondary Ion Mass Spectroscopy (SIMS), it was shown that, under the RF deuterium plasma treat- 
ment at $250{ }^{\circ} \mathrm{C}$ for $30 \mathrm{~min}$, deuterium from the plasma can be incorporated into the subsurface layer of the $\mathrm{Si}$ substrate of the silicon-on-insulator (SOI) structure with thicknesses of the Si layer and the buried oxide (BOX) of about, respectively, 200 and $400 \mathrm{~nm}$ (see Fig. 9a). Under the employed regime, deuterium is embedded mainly in the $\mathrm{BOX} /$ silicon film and the $\mathrm{BOX} /$ silicon substrate interfaces, and its distribution corresponds to a nonstoichiometric composition of BOX [56] (Fig. 9a and $9 \mathrm{~b})$. The deuterium concentration inside of $\mathrm{BOX}$ reaches $1 \cdot 10^{17} \mathrm{at} / \mathrm{cm}^{3}$ and more.

The performed experiments evidence that, during the RF plasma treatment, hydrogen in the form of atomic hydrogen or protons enters the multilayer $\mathrm{SiO}_{2}-\mathrm{Si}$ structure both from dioxide and from the RF plasma and can diffuse into the structure on large distances (up to $1 \mu \mathrm{m})$. Under such a treatment, hydrogen is mainly collected in the $\mathrm{SiO}_{2}-\mathrm{Si}$ interfaces and at various defects associated with a nonstoichiometry of the $\mathrm{SiO}_{2}$ matrix.
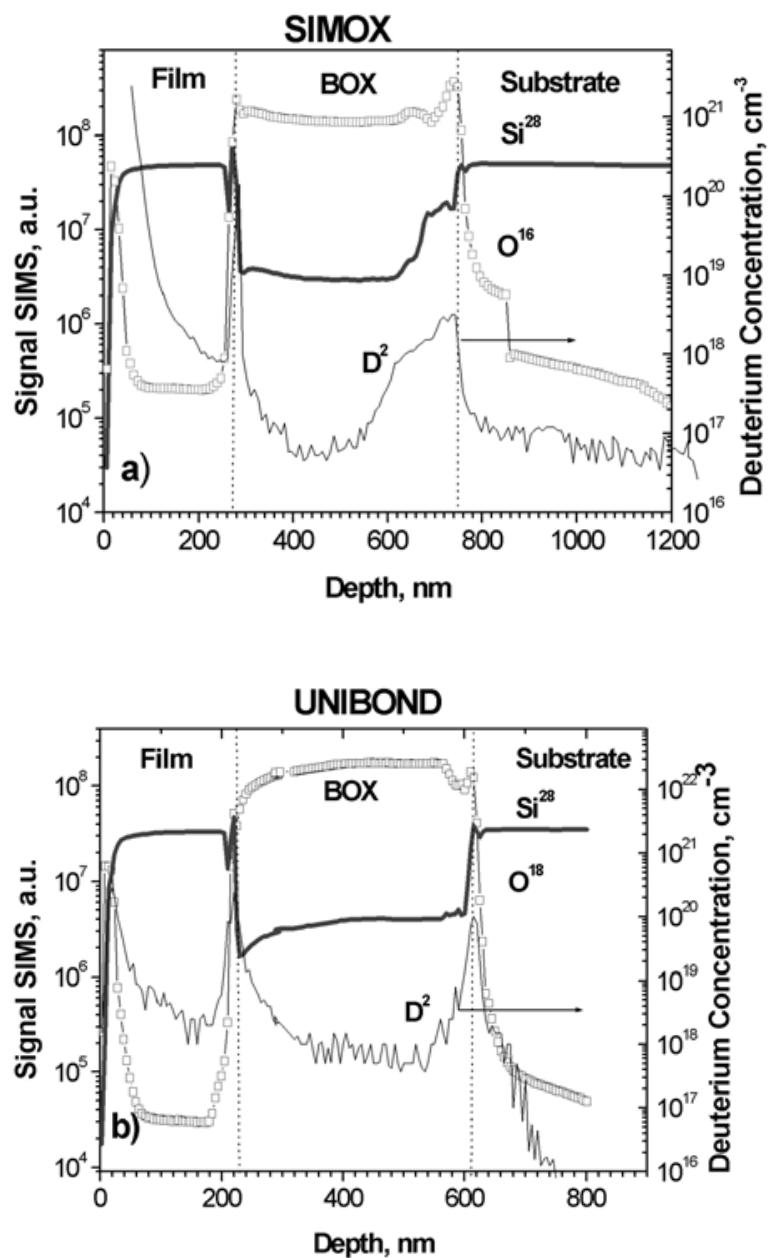

Fig. 9. The SIMS distribution of deuterium, oxygen, and silicon in SOI structures fabricated by SIMOX (a) and UNIBOND (b) techniques which was measured after deuteration at $250{ }^{\circ} \mathrm{C}$ during $30 \mathrm{~min}$ (RF specific power$\left.1 \mathrm{~W} / \mathrm{cm}^{2}\right)[56]$.

\section{3. $\mathrm{SiO}_{2}-\mathrm{Si}$ interface transformation under plasma treatment}

The RF plasma treatment considerably decreases the surface state (SS) concentration in the $\mathrm{SiO}_{2}-\mathrm{Si}$ interface $[9,57,58]$. It was shown in $[9,57]$ that there is a definite duration and a specific power of the process that leads to a minimum SS concentration (Fig. 10). The similar dependence of the SS concentration vs. the treatment duration and the temperature is also revealed under the low-temperature hydrogen annealing of $\mathrm{Al}_{-} \mathrm{SiO}_{2}-\mathrm{Si}$ structures [59-61] and can be explained by the competition of two processes: first, the neutralization of dangling bonds by atomic hydrogen in the $\mathrm{SiO}_{2}-\mathrm{Si}$ interface [61-63]

$\mathrm{Si}_{3} \equiv \mathrm{Si}-+\mathrm{H} \rightarrow \mathrm{Si}_{3} \equiv \mathrm{Si}-\mathrm{H}$

and, second, the break of $\mathrm{Si}-\mathrm{H}$ bonds [62]

$\mathrm{Si}_{3} \equiv \mathrm{Si}-\mathrm{H} \rightarrow \mathrm{Si}_{3} \equiv \mathrm{Si}-+\mathrm{H}$

or the depassivation of dangling bonds [63]

$\mathrm{Si}_{3} \equiv \mathrm{Si}-\mathrm{H}+\mathrm{H} \rightarrow \mathrm{Si}_{3} \equiv \mathrm{Si}-+\mathrm{H}_{2}$.
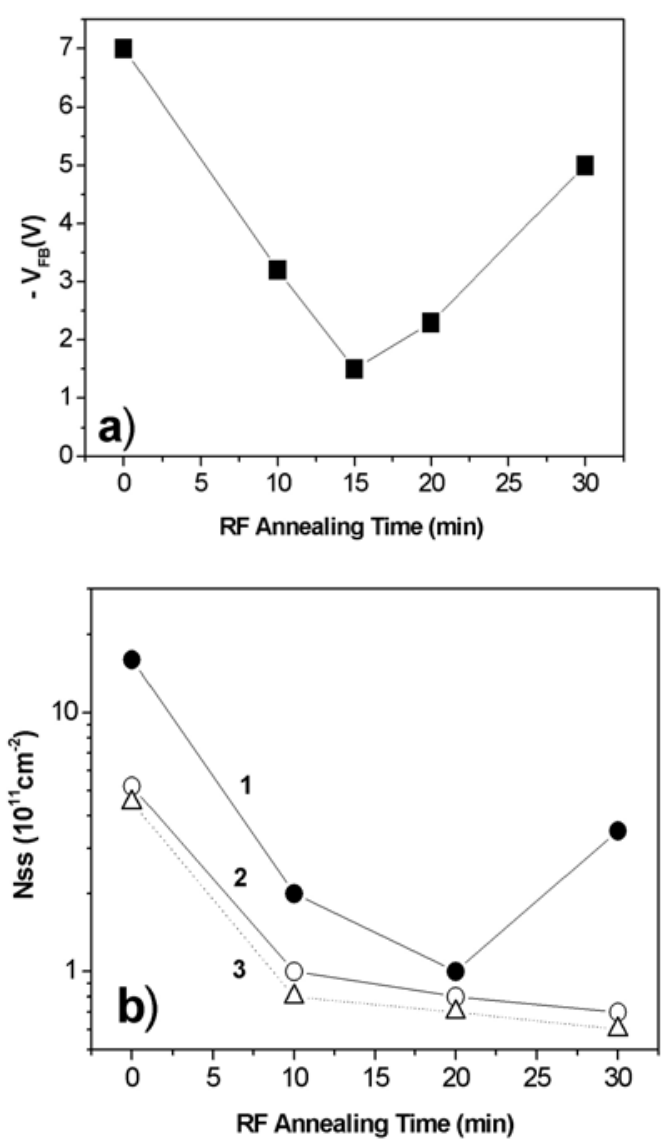

Fig. 10. (a) "Flat band" voltage and (b) the surface state density versus the time of the RF plasma treatment of initial $\mathrm{Al}-\mathrm{SiO}_{2}-\mathrm{Si}$ structures. The dependences are obtained by measuring the reverse sweep plateau of low-temperature $C-V$ characteristics $(\bullet)$, by TSCR method (o), and by the GrayBrown method $(\Delta)$ [57]. 
Table 1. Energy position $\left(E_{a}\right)$ and concentration $\left(N_{t}\right)$ of levels in the transition layer on the $\mathrm{SiO}_{2}$-Si interface which are created under RF plasma treatment at a specific power of $1.5 \mathrm{~W} / \mathrm{cm}^{2}$.

\begin{tabular}{|c|c|c|c|c|c|}
\hline \multirow{2}{*}{$E_{a}(\mathrm{eV})$} & \multicolumn{3}{|c|}{$\begin{array}{c}N_{t} \times 10^{9}\left(\mathrm{~cm}^{-2}\right) \\
\text { Treatment time }(\mathrm{min})\end{array}$} & $\begin{array}{c}\text { Plausible } \\
\text { nature } \\
{[47]}\end{array}$ \\
\cline { 2 - 5 } & 0 & 10 & 15 & 30 & \\
\hline$E_{c}-0.013$ & 0.90 & 0.45 & - & - & \\
\hline$E_{c}-0.032$ & 9.5 & 1.2 & - & - & \\
\hline$E_{c}-0.040$ & - & - & - & 1.2 & \\
\hline$E_{c}-0.045$ & 4.8 & 6.2 & 25.0 & 28.0 & $\begin{array}{c}\text { Si-H } \\
\text { local phonon }\end{array}$ \\
\hline$E_{c}-0.062$ & - & - & - & 9.0 & \\
\hline$E_{v}+0.013$ & 1.26 & 0.3 & - & - & \\
\hline$E_{v}+0.025$ & - & - & - & 2.0 & \\
\hline$E_{V}+0.032$ & 5.2 & 4.2 & - & 5.0 & \\
\hline$E_{V}+0.045$ & 3.0 & 3.7 & 39.0 & 5.0 & $\begin{array}{c}\text { Si-OH } \\
\text { local phonon }\end{array}$ \\
\hline$E_{v}+0.062$ & - & - & - & 3.5 & \\
\hline$E_{v}+0.071$ & - & - & - & 3.2 & \\
\hline
\end{tabular}

It was shown in [62] that reactions (1) and (3) are exothermic and have to be thermally activated. In the case of atomic hydrogen, the reaction barrier for the passivation reaction (1) is lower than that for the depassivation reaction (3) [63]. The proposed concurrent process of atomic hydrogen neutralization during its diffusion through oxide [61] seems to be impossible in our case.

The atomic hydrogen accumulation at the $\mathrm{SiO}_{2}-\mathrm{Si}$ interface during the plasma treatment of $\mathrm{Al}-\mathrm{SiO}_{2}-\mathrm{Si}$ structures in the nitrogen atmosphere has been demonstrated in [44]. The effect of hydrogen on the plasma annealing of SS has also been pointed in work [64], in which the oxygen plasma has been used.

The thermally stimulated charge release (TSCR) method applied to the $\mathrm{Al}-\mathrm{SiO}_{2}$ - $\mathrm{Si}$ structures at cryogenic temperatures (from 4.2 to $20 \mathrm{~K}$ ) allows the authors of work [9] to analyze the interface transformation process under the RF forming gas plasma treatment. The current peaks observed by the TSCR technique at cryogenic temperatures are related to the charge release from a $\mathrm{SiO}_{2}$-Si transition layer with generation of local phonons [65]. The number and amplitude of these peaks characterize the number and magnitude of the strained and dangling bonds in this region. In Table 1, the data on the shallow levels in the $\mathrm{SiO}_{2}$ - $\mathrm{Si}$ transition layer after the RF plasma treatments of various durations are presented. In 15 minutes after the RF action on the structure, only two shallow levels with the energies $E_{c}-0.045 \mathrm{eV}$ and $E_{v}+0.045 \mathrm{eV}$ are retained. So, the $\mathrm{SiO}_{2}-\mathrm{Si}$ interface has an ordered structure with a small number of distortions. The observed two levels have been presumably related to $\mathrm{Si}-\mathrm{OH}$ and $\mathrm{Si}-\mathrm{H}$ bonds, respectively [66], which are electrically neutral. Indeed, if we subtract the concentration of the $0.045-\mathrm{eV}$ levels from the total concentration of shallow levels obtained by the TSCR method, the obtained magnitude is fully correlated with

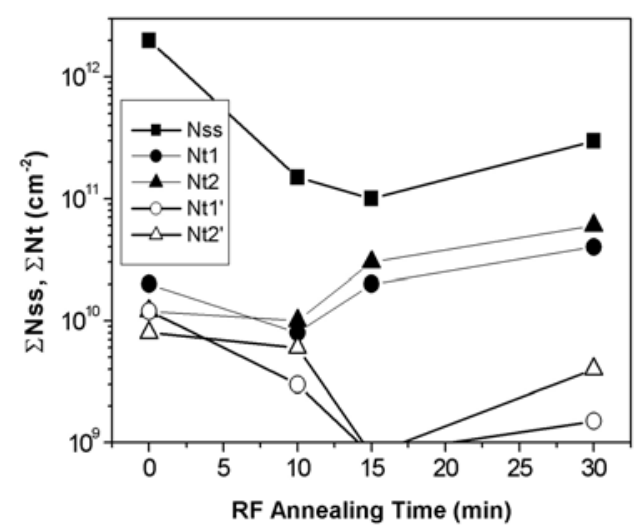

Fig. 11. Integral concentration of electron surface traps, $\Sigma N_{S S}$, (a) and the total concentration of shallow traps, $\Sigma N_{t}$, near the c- $(\bullet)$ and v-zones $(\boldsymbol{\Delta})$, the total concentration of shallow traps near the c-zone without accounting for the $E_{c}-0.045 \mathrm{eV}$ level ( $(\circ)$ and the total concentration of the shallow traps near the v-zone without accounting for the $E_{v}+0.045 \mathrm{eV}$ level $(\Delta)$ versus the RF treatment time at $P=1.5 \mathrm{~W} / \mathrm{cm}^{2}[9]$.

the total SS concentration measured by the quasistatic $C-V$ technique [67] (see Fig. 11). Thus, it can be suggested that the RF plasma treatment except for the surface state passivation leads to the structural ordering of the transition layer and the $\mathrm{SiO}_{2}-\mathrm{Si}$ interface.

The following results also provide the arguments for this conclusion. The effect of $\gamma$-radiation on the RFplasma-treated $\mathrm{Al}-\mathrm{SiO}_{2}-\mathrm{Si}$ and $\mathrm{Al}-$ polySi-SiO $\mathrm{S}_{2}-\mathrm{Si}$ structures gives rise to the formation of a lower surface state concentration than that in the untreated structures [68]. If the RF plasma only passivates the surface states, the following irradiation has to lead to a deterioration of the radiation hardness of these structures [69]. Thus, the employed regimes of RF plasma treatment result in the ordering of $\mathrm{SiO}_{2}-\mathrm{Si}$ interfaces and not only in the passivation but also in the annealing of SS.

\section{RF plasma effect on the properties of $\mathrm{SiO}_{2}$}

At the beginning of the 1970 s, the researches of the lowenergy plasma-ion etching of metals or oxides in the $\mathrm{SiO}_{2}$-Si structures showed [37] that ion-beam-assisted plasma etching leads to considerable degradation phenomena: an increase of the leakage current through the dielectric; the building-up of a positive fixed charge near the $\mathrm{SiO}_{2}-\mathrm{Si}$ interface; and the activation of charge transport in the dielectric. However, the following improvement of the equipment and the elaboration of new technological regimes allow one to realize the technologies of plasma treatment leading not only to a simply annealed oxide charge [70] but also to a significant improvement of the $\mathrm{SiO}_{2}$-Si properties, for instant: a considerable reduction of the positive fixed charge in the dielectric $[2,8,57,68]$; a decrease of ion charge transport in dioxide [71]; a better quality of the $\mathrm{Si}$ nanocrystals $/ \mathrm{SiO}_{2}$ amorphous matrix interface $[10,11]$, a 
considerable decrease of the positive charge building-up in oxide after the following irradiation [68], and an increase of the lifetime of metal-oxide-silicon lightemitting diodes (MOSLEDs) operating under high-field electron injection $[72,73]$. Let us consider consistently these phenomena.

\subsection{Charge annealing in gate oxide}

$\mathrm{RF}$ plasma treatment of the $\mathrm{Al}-\mathrm{SiO}_{2}-\mathrm{Si}$ structure from the side of the aluminum gate (front side) results in a reduction of the "flat-band" and "mid-gap" voltages in its capacitance-voltage $(C-V)$ characteristics (Fig. 12) [68], that is directly related to the oxide charge [74]. The gas composition in a plasma discharge does not affect sufficiently the minimal magnitude of these parameters. However, the hydrogen influence in the plasma atmosphere during the RF plasma annealing on the oxide charge in the Al-polySi-SiO ${ }_{2}-\mathrm{Si}$ structure is more significant [68]. The important point is the existence of a minimum in the positive charge dependence (as in the case of SS) on the specific power of plasma discharge for $\mathrm{Al}-\mathrm{SiO}_{2}-\mathrm{Si}$ structures.

The decrease of the "flat-band" and "mid-gap" voltages in a MIS capacitor can be associated with both positive fixed charge decrease and a shift of mobile positive charge ions in oxide towards the metallic electrode [75]. The influence of the discharge atmosphere on the final amount of the "flat-band" and "mid-gap" voltages attests about the positive charge reduction in oxide. In addition, this position is supported by EPR measurements [20]. The minimal used intensity of RF plasma treatment gives rise to the full neutralization of E'centers in the thermal oxide of the phosphorus-implanted $\mathrm{SiO}_{2}-\mathrm{Si}$ structure (Fig. 13). At the same time, the thermal annealing in nitrogen at $450{ }^{\circ} \mathrm{C}$ does not lead to the full annealing of these centers. It is worth noting that E'centers have been identified as positively charged relaxed oxygen vacancies in $\mathrm{SiO}_{2}[76,77]$. In addition, the E'-

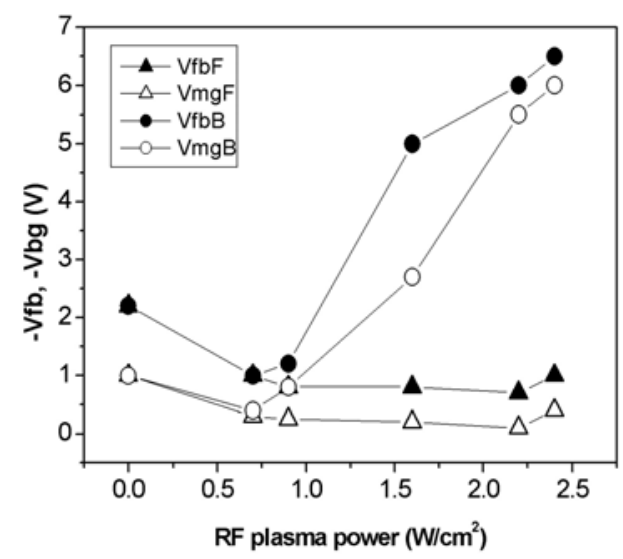

Fig. 12. "Flat band" voltage $(\boldsymbol{\Lambda}, \bullet)$ and "mid-gap" voltage $(\Delta, 0)$ as a function of the power density of RF plasma treatment for the front side $(\Delta, \mathbf{\Delta})$ and the back side $(\mathrm{o}, \bullet)$ of a sample $\left(t=15 \mathrm{~min}, T_{\text {heat }}=230^{\circ} \mathrm{C}\right)$.

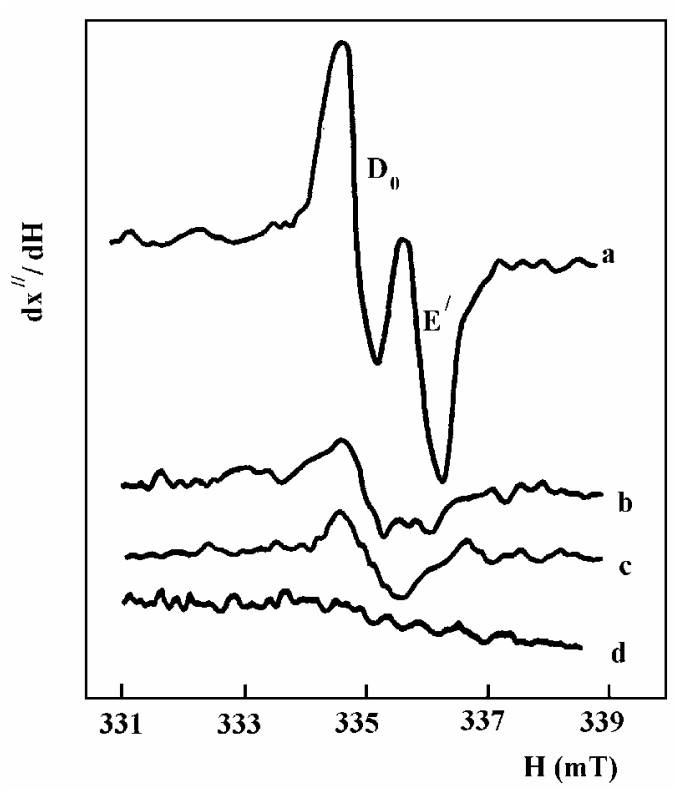

Fig. 13. EPR spectra of $\mathrm{D}_{0^{-}}(g=2.0055)$ and $\mathrm{E}^{\prime}-(g=2.0005)$ centers measured on $\mathrm{P}^{+}$ion-implanted $\mathrm{SiO}_{2}-\mathrm{Si}$ structures $\left(E=120 \mathrm{keV} ; D=1 \times 10^{14}\right.$ ions $\left./ \mathrm{cm}^{2}\right)$ : a) after implantation; b) after thermal annealing $\left(T=450{ }^{\circ} \mathrm{C}, t=20 \mathrm{~min}\right)$; c) after RF plasma treatment $\left(P=0.9 \mathrm{~W} / \mathrm{cm}^{2}, t=15 \mathrm{~min}\right)$; d) after RF plasma treatment $\left(P=2.2 \mathrm{~W} / \mathrm{cm}^{2}, t=15 \mathrm{~min}\right)[20]$.

center concentration and localization have a good correlation with the magnitude and the localization of the fixed positive charge in the irradiated thermal oxide [78]. Thus, the RF plasma treatment can indeed anneal or passivate (neutralize) the positive charge in oxide.

\subsection{RF plasma effect on moving charges in $\mathrm{SiO}_{2}$}

When a sufficient concentration of mobile positive ions (such as $\mathrm{Na}^{+}$or $\mathrm{K}^{+}$) is located in oxide of the $\mathrm{SiO}_{2}-\mathrm{Si}$ structure, the RF plasma treatment leads to a shift of ions towards the treated surface. The results of investigations of the thermally stimulated polarization joined with the $C-V$ technique performed on the Al-polySi- $\mathrm{SiO}_{2}-\mathrm{Si}$ structures attest this conclusion [71]. Indeed, it was shown that the RF plasma treatment of the structures from the side of the aluminum electrode (front side) reduces significantly the "flat-band" voltage of MIS capacitors. However, the following heating of a structure up to $400{ }^{\circ} \mathrm{C}$ with a positive bias applied to the metal electrode restores its initial magnitude.

This idea is also supported by $C-V$ measurements of MIS structures treated by RF plasma from the front side and the back side (silicon substrate) (Fig. 12). One can see that RF plasma treatment of the front side of a structure results in a decrease of the "flat-band" voltage, and the same treatment from the back side causes an increase of this amount. The presented results can be explained by the negative charging of the treated surface of a sample relative to the surface located on the RF electrode. In addition, at the used treatment regimes, the sample is heated up to $300{ }^{\circ} \mathrm{C}$ (see Fig. 5). Thus, such joint effect of 
the electric field and the temperature has to result in a shift of positively charged ions towards the treated surface.

In the case of $\mathrm{Al}-\mathrm{SiO}_{2}$-Si structures, such a treatment of the front side led to the $\mathrm{Na}^{+}$ion getting by the $\mathrm{Al}-\mathrm{SiO}_{2}$ transition layer [71] that increased considerably the high-temperature bias-temperature stability of the structures.

\subsection{Neutralization of a positive charge in the buried oxide}

Since a lot of various types of microelectronic devices and integrated circuits (ICs) is fabricated on SOI wafers at the present time [79], the study of the charge trapping in different parts of this system and the development of methods of neutralization or annealing of this trapped charge are the very important tasks. Especially, it is difficult to anneal the charge accumulated in BOX during the device operation because of the necessity to treat a totally fabricated device or IC. The RF hydrogen plasma treatment is very attractive in this case. The positive charge accumulation in the BOX of SOI $n$-channel MOSFET results in both the generation of a parasitic back channel in the partially depleted devices and a shift of the threshold voltage towards positive gate voltages in a fully depleted SOI MOSFET [80].
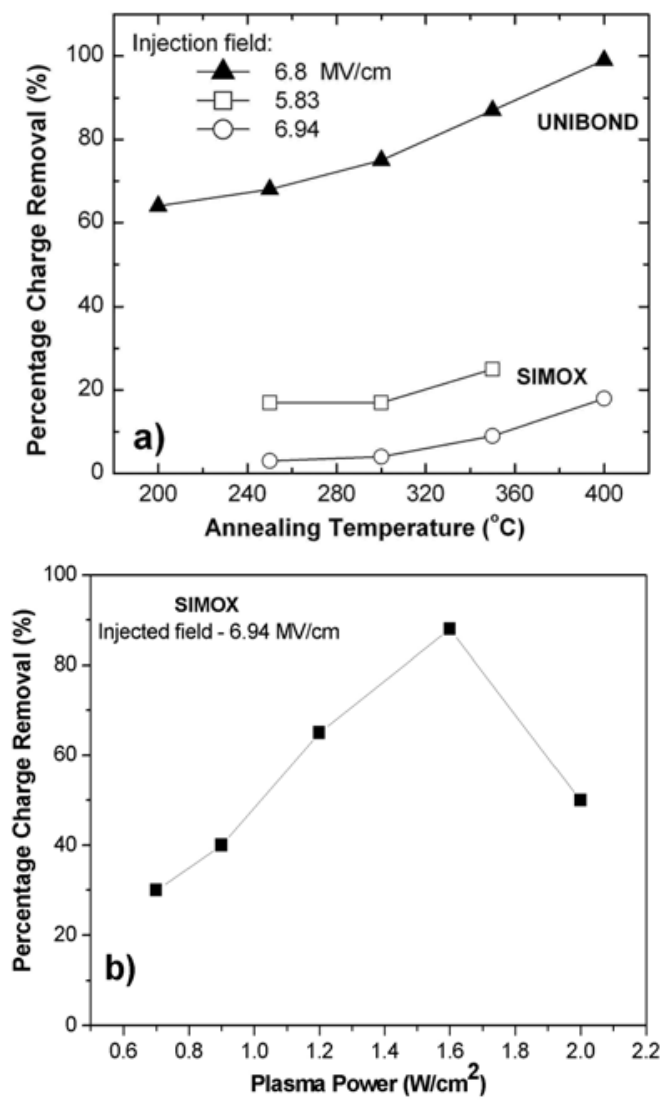

Fig. 14. Percentage of annealed charge in the BOX of UNIBOND and SIMOX SOI structures as a function of the annealing temperature (a) and a function of the RF plasma power (b) for different injecting electric fields [41].
In works [41, 81], it was shown that the high-field electron injection in the BOX of SOI structures fabricated both by the single implanted (SI) SIMOX and UNIBOND technologies generates a positive charge in the dielectric located mainly near the BOX/substrate interface. In case of the SI SIMOX SOI structure, only $30 \%$ of the generated positive charge can be thermally annealed at $400{ }^{\circ} \mathrm{C}$ for $15 \mathrm{~min}$ (Fig. 14a). An increase of the injecting electric field reinforces the thermal stability of a generated positive charge, which is the evidence for a more complicated structure of the defects generated at the highfield electron injection. Using the RF forming gas plasma treatment resulted in the $90-\%$ annealing of this positive charge at $1.6 \mathrm{~W} / \mathrm{cm}^{2}$ (Fig. 14b). At this power density, the SOI wafer was heated only up to $350^{\circ} \mathrm{C}$ (see Fig. 5), which evidences the strong nonthermal processes appearing during the RF plasma treatment. It was suggested both the hydrogen-enhanced [41] and recombination-enhanced [82] processes of annealing of defects take place in the above-mentioned case.

\subsection{Effect of RF plasma treatment on nanostructured oxide}

The effective RF hydrogen plasma annealing of SS on the $\mathrm{SiO}_{2}$-Si interface [9] assumes a possibility to employ the RF plasma treatment in order to increase the luminescence and to control the size of Si nanocrystals embedded into the dioxide matrix. Since the RF plasma treatment is a low-temperature process and decreases strongly both the defect concentration inside the amorphous oxide matrix and the SS concentration on the interfaces, but does not affect the size or properties of nanoinclusions, the use of such a treatment allows us to distinguish luminescent mechanisms related to the light emission of nanocrystals contained in the amorphous matrix (the exciton luminescence from nanocrystals [83] or the radiative recombination via defects in silicon oxide surrounding Si nanocrystals or at the interface [84]).

It was demonstrated in [11] that the RF forming gas plasma treatment allows one to induce a photoluminescence (PL) from Si nanocrystals embedded into the $\mathrm{SiO}_{2}$ matrix without shifting the PL intensity maximum position (Fig. 15). It should be noted that the enhancement of the PL intensity in case of the RF plasma treatment exceeded considerably the influence of thermal annealing in the hydrogen atmosphere at $500{ }^{\circ} \mathrm{C} \mathrm{[11],} \mathrm{and} \mathrm{the}$ maximal enhancement of the intensity for the plasma treatment reached up to the 30 -fold value. The temperature held under the generation of Si nanocrystals was $950{ }^{\circ} \mathrm{C}$, and their size was estimated as $4.3 \mathrm{~nm}$ [85]. In case of the creation of $\mathrm{Si}$ nanocrystals in dioxide by the $\mathrm{Si}^{+}$ion implantation and the high-temperature annealing at $1200{ }^{\circ} \mathrm{C}$ for $15 \mathrm{~min}$, the effect of the RF plasma treatment on the PL intensity related to the exciton recombination in the nanocrystals was sufficiently visible (more than 3 -fold enhancement) [10] and exceeded that under the thermal annealing in a forming gas at $450{ }^{\circ} \mathrm{C}$ [86] but was not such significant as in the above-mentioned case. At the 


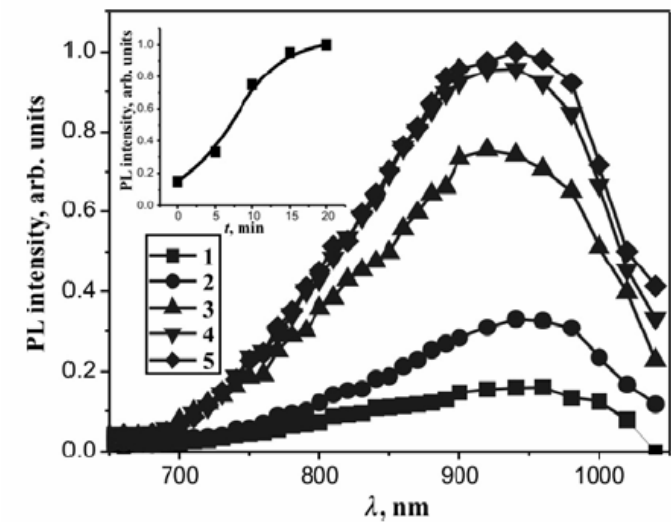

Fig. 15. PL spectra of normally deposited samples annealed at $950^{\circ} \mathrm{C}$ and treated with $\mathrm{RF}$ plasma for various times: nontreated (curve 1), treated for 5 (2), 10 (3), 15 (4), and $20 \mathrm{~min}$ (5). Insert: the PL peak intensity versus the plasma treatment time [11].

same time, no increase of the PL intensity for amorphous $\mathrm{Si}$ inclusions that was obtained by the $700{ }^{\circ} \mathrm{C}$-annealing of a $\mathrm{SiO}_{\mathrm{x}}$ film deposited on a $\mathrm{Si}$ wafer by thermal evaporation of $\mathrm{SiO}$ in vacuum was observed [11]. The obtained results can be interpreted in the frame of the model of radiation ordering of the $\mathrm{SiO}_{2}-\mathrm{Si}$ interface [87] surrounding a Si nanocrystal with participation of atomic hydrogen and defect recharging that appears during the RF plasma treatment. An increase of the thermal annealing temperature improves a quality of the Si nanocrystal $/ \mathrm{SiO}_{2}$ matrix interface. Probably, the $\mathrm{Si}$ amorphous nanoinclusions don't have a lot of broken bonds on the interface with the amorphous matrix.

The phenomenon of increasing the quality of the nanocrystal/amorphous matrix interface after the RF hydrogen plasma treatment is observed not only for the $\mathrm{Si}$ nanocrystals $/ \mathrm{SiO}_{2}$ amorphous matrix system and for other crystalline semiconductor nanodots/amorphous glasses ones. For example, glasses doped by $\mathrm{CdSSe}$ nanocrystals with sizes from 2.65 to $7.80 \mathrm{~nm}$ shows an increase of the exciton PL from the nanocrystals after the RF plasma treatment even for thick samples with thickness more $1 \mathrm{~mm}$ [88]. Thus, it is possible to conclude that the proposed plasma treatment can be effectively employed for increasing the quality and the annealing of dangling $\mathrm{Si}$ bonds in crystalline semiconductor nanodot/amorphous matrix interfaces.

\section{5. $R F$ plasma effect on light-emitting $\mathrm{SiO}_{2}$ layers implanted with impurities of the IV group}

The development of Si-based light-emitting devices has recently gained in importance due to the need for efficient and inexpensive light sources, whose production is fully compatible with the existing silicon device technology. An improved version of MOS-based light-emitting devices (MOSLED) consists of a silicon substrate having a few hundred nm-thick layer of thermally grown $\mathrm{SiO}_{2}$, which is then ion-implanted with Ge and heat-treated by rapid thermal annealing (RTA) [89]. This MOSLED typically uses transparent indium tin oxide (ITO) on the top of a $\mathrm{SiO}_{2}$ layer, and an $\mathrm{Al}$ layer on the back of the $\mathrm{Si}$ substrate as the current injecting electrodes. An important feature of a Ge ion-implanted and RTA-treated MOSLED is its ability to emit violet light (at the wavelength $\lambda=$ $390 \mathrm{~nm}$ ) of appreciably high intensities [89].

Critical issues of the MOSLED performance are the device durability in terms of the device operating lifetime which has to be improved and the strong-field injectionassociated oxide degradation which has to be prevented or at least retarded [90, 91]. To increase the operation duration of the MOSLEDs, it was suggested to use the RF hydrogen plasma treatment [72, 73, 92]. It should be noted that mechanisms of violet electroluminescence (EL) is the impact ionization of neutral oxygen-deficient centers (ODC), in one of which the oxygen atoms of the original $\mathrm{Si}-\mathrm{O}-\mathrm{Si}$ bonding configuration are removed allowing the $\mathrm{Si}$ atoms to be subsequently replaced by added $\mathrm{Ge}$ atoms to form $\mathrm{Si}-\mathrm{Ge}$ and $\mathrm{Ge}-\mathrm{Ge}$ bonds [89]. In this connection, the optimal regimes of the RF plasma treatment of totally fabricated MOSLED were found, which resulted in ordering the $\mathrm{SiO}_{2}$ matrix without annealing the defect-involved luminescent centers (LCs). The plasma treatment allowed one to extend the maximal explotable current density by more than a factor of 10 , which resulted in a considerable increase of the maximal EL intensity (Fig. 16) and an increase of the durability of MOSLEDs by more than a factor of four (Fig. 17).

In case of the combined implantation by $\mathrm{Si}^{+}$and $\mathrm{C}^{+}$ ions in order to form $\mathrm{SiC}$ nanoclusters in dioxide, the plasma treatment on the last stage of the MOSLED fabrication resulted in a reduction of the EL intensity in the wavelength range from 400 to $650 \mathrm{~nm}$ that attested the defect nature of the observed LCs (Fig. 18) [93]. At the same time, the durability of MOSLEDs increased by more than factor five (Fig. 19), which evidences the improvement of the $\mathrm{SiO}_{2}$ matrix quality. Thus, the RF plasma treatment except for the positive charge neutralization in thin $\mathrm{SiO}_{2}$ layers leads in some regimes to the annealing of structural defects in the $\mathrm{SiO}_{2}$ matrix and so to ordering the amorphous network in $\mathrm{SiO}_{2}$.

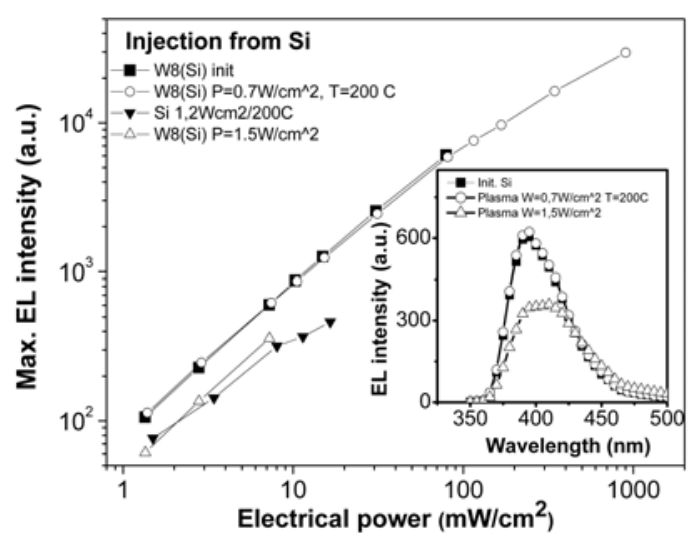

Fig. 16. Variation of the maximal EL intensity with current density measured at a wavelength of $390 \mathrm{~nm}$ before and after plasma treatment for electrons injected from $\mathrm{Si}$ substrate. Inset: EL specta of Ge-implanted $\mathrm{SiO}_{2}$ before and after plasma treatment [72]. 


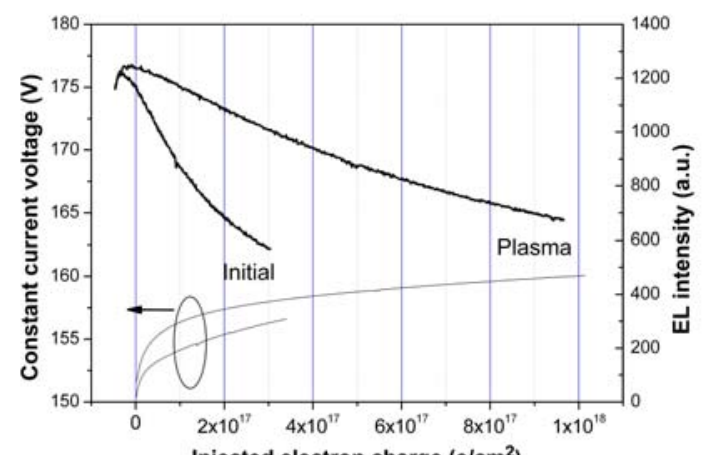

Fig. 17. EL intensity measured at a wavelength of $390 \mathrm{~nm}$ and a constant current voltage as a function of the electron-injected charge before and after plasma treatment for a current density of $2 \times 10^{-5} \mathrm{~A} / \mathrm{cm}^{2}$ (plasma power density $-0.7 \mathrm{~W} / \mathrm{cm}^{2}$, additional heating $\left.-200^{\circ} \mathrm{C}\right)[72]$
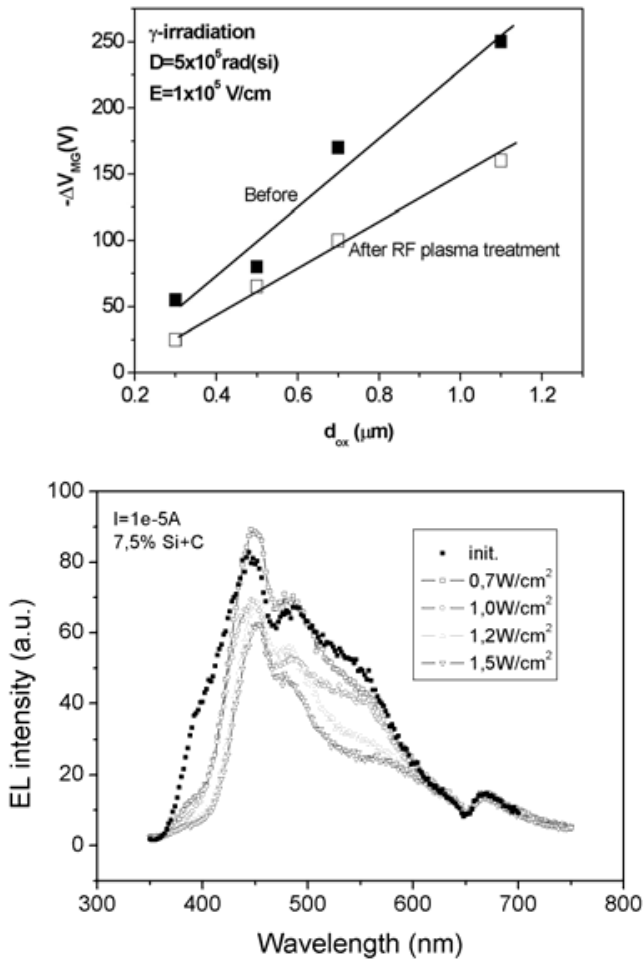

Fig. 18. EL spectra of the samples implanted by $\mathrm{Si}^{+}+\mathrm{C}^{+}$ions before and after hydrogen plasma treatment during $15 \mathrm{~min}$ [93].

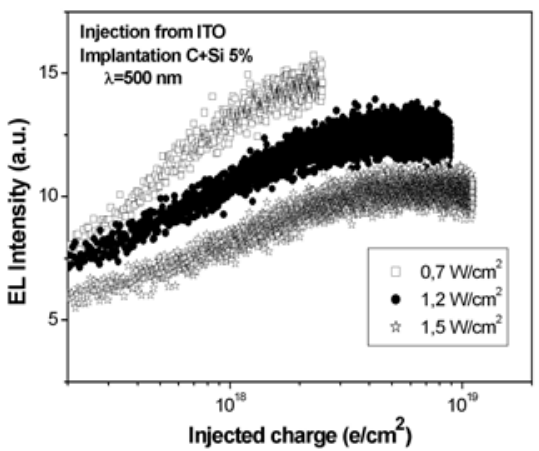

Fig. 19. EL intensity at a wavelength of $500 \mathrm{~nm}$ as a function of the electron-injected charge after hydrogen plasma treatment of $\mathrm{SiO}_{2}$ coimplanted with $\mathrm{Si}^{+}$and $\mathrm{C}^{+}[93]$.
4.6. Ordering the $\mathrm{SiO}_{2}$ network structure and models of ordering

Except for the above-presented examples of the increase of the operation stability of a gate and buried oxides and oxides employed as a light-emitting material, the following effects strongly support the assumption that the RF plasma treatment promotes the creation of an amorphous matrix with minimal structural defect concentration and maximal binding energy. Indeed, using the plasma-chemical deposition technique and the following RF plasma treatment in the oxygen atmosphere, dense silicon dioxide with structural and electrical parameters similar to those of thermally grown oxide can be fabricated at low temperatures (up to $400{ }^{\circ} \mathrm{C}$ ) [94].

The treatment of $\mathrm{Al}-\mathrm{SiO}_{2}-\mathrm{Si}$ structures which do not maintain a mobile positive charge in $\mathrm{SiO}_{2}$ results in the electron trap annealing [95]. A part of these traps (with capture cross-sections of $3.3 \times 10^{-16}, 3.5 \times 10^{-15}$, and $2.6 \times 10^{-14} \mathrm{~cm}^{2}$ ) was produced by electron beam irradiation, and some ones were initially located in oxide. The research has been performed by the avalanche injection of electrons into $\mathrm{SiO}_{2}$. After the RF plasma impact, the electron trapping in $\mathrm{SiO}_{2}$ considerably decreases. In work [68], it was also shown that, after the RF plasma treatment, the following $\gamma$-irradiation has been built up a considerably smaller positive charge into $\mathrm{SiO}_{2}$ than into the initial structure (Fig. 20). In the case of hydrogen neutralization, the contrary result has to be appeared [96].

The ordering effect can be explained by following alternative models. The first one $[18,19]$ takes the process of electron and hole injection into a dielectric during the RF treatment into account. Due to such an injection, the enhanced recombination of electron-hole pairs on the oxide network defects and the energy extraction in these local places can take place. Thus, this model uses the mechanism of recombination-enhanced defect reactions depicted in works [82, 97].

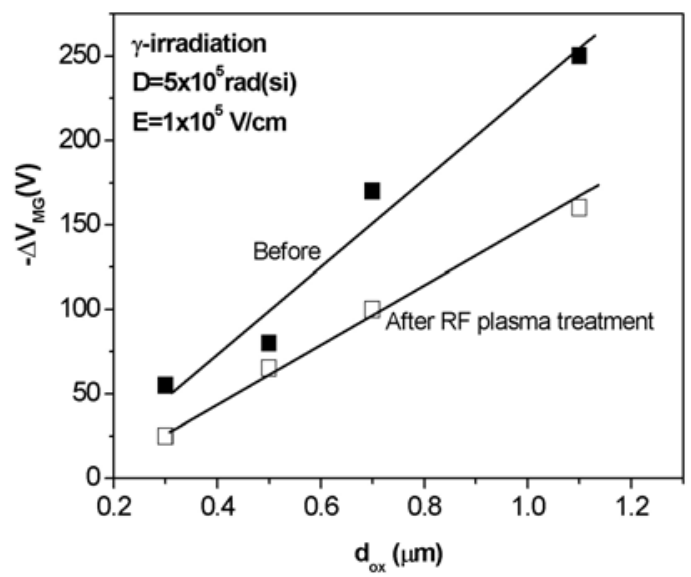

Fig. 20. "Mid-gap" voltage shifting as a function of the oxide thickness for the Al-polySi-SiO 2 -Si structures subjected to $\gamma$ irradiation $\left(D=5 \times 10^{5} \mathrm{rad}(\mathrm{Si}), E_{\mathrm{ox}}=1 \times 10^{5} \mathrm{~V} / \mathrm{cm}\right)$ [68]. 
The second model [68] considers both the charge carrier trapping in strained bonds in $\mathrm{SiO}_{2}$ and the hydrogen effect on the relaxation processes of inner stresses in the $\mathrm{SiO}_{2}$ amorphous network [96]. It was suggested that hydrogen extracting in $\mathrm{SiO}_{2}$ in the atomic form during the RF plasma treatment, together with a hole or without it, is trapped in strained Si-O-Si bonds and broke up these bonds to form both $\mathrm{Si}-\mathrm{H}$ and $\mathrm{Si}-\mathrm{OH}$ bonds. In addition, hydrogen also passivates $\mathrm{O}_{3} \equiv \mathrm{Si}$ - and $\mathrm{O}_{3} \equiv$ Si-O- dangling bonds. These processes give rise to the dioxide amorphous network relaxation to a structure with minimal potential energy. On this step, the process is not yet finished. The following electron trapping in Si$\mathrm{H}$ and $\mathrm{Si}-\mathrm{O}-\mathrm{H}$ bonds results in the hydrogen release from the bonds [98], and, after the hole trapping, the production of unstressed $\mathrm{Si}-\mathrm{O}-\mathrm{Si}$ bonds is finished. Thus, in the last model, hydrogen plays role of a "mediator" leading to the mechanical stress relaxation in $\mathrm{SiO}_{2}$.

It should be noted that the UV irradiation itself is also capable for a transformation of the defected oxide network structure [87]. The nature of this effect is not yet understandable now; however, this phenomenon has to be taken into account in the RF plasma annealing analysis.

\section{Plasma annealing of the ion-implanted subsurface silicon layer}

\subsection{Plasma influence on defects in the subsurface silicon layer}

It was revealed that the RF plasma treatment of $\mathrm{Al}-\mathrm{SiO}_{2}-$ $\mathrm{Si}$ structures with hydrogen or nitrogen plasma gives rise to the atomic hydrogen saturation of the subsurface silicon layer [20, 30, 44, 99]. The processes of interaction of hydrogen with defects in semiconductors and semiconductor structures can be divided into two main types.

The first one includes the processes of transformation of the electrical activity during the direct chemical binding of hydrogen with the defect. The following phenomena can be related to such a kind of processes: 1) hydrogen shallow doping impurity neutralization [26]; 2) full neutralization of radiation defects and impurities creating the deep levels in the forbidden silicon gap [23]; 3) partial neutralization or even electrical activation of various defects and impurities in semiconductors $[26,100]$; 4) hydrogen neutralization of dangling bonds in a-Si:H [101]. A specific peculiarity of these processes is the restoration of a defect electrical activity after the high-temperature vacuum annealing, which leads to the breaking-up of the hydrogen-defect chemical bonds and the restoration of the initial structure of a defect.

The second type of the processes includes those, in which hydrogen takes part as a catalyst during the reaction. That is, hydrogen promotes the defect transformation reaction. After finishing the reaction, it leaves a place of the reaction, but the defect structure is changed.
To such phenomena, we can relate: 1) suppressing the swirl defect creation under silicon growth in the hydrogen ambient [102]; 2) hydrogen-enhanced thermal donor creation in the hydrogen atmosphere or under hydrogen plasma treatment [103, 104]; 3) enhanced annealing of radiation defects in hydrogenated crystalline silicon [105] and under RF plasma treatment [14]; 4) enhanced dopant activation under RF plasma effect [15] or additional hydrogen implantation with following thermal annealing [106, 107]. A specific peculiarity of these phenomena is the lack of the restoration of defect properties after the following thermal annealing.

Let us consider the first group of the processes. These processes have been widely outlined [22-27, 30], and we will touch them only shortly.

\subsection{Hydrogen neutralization of electrical active defects and impurities in silicon.}

For the first time, the deep level neutralization by hydrogen plasma was revealed in work [13], where it was shown that deep levels produced in silicon by laser irradiation are more effectively neutralized by hydrogen plasma than by the thermal annealing in molecular hydrogen. The following thermal annealing in vacuum at $400{ }^{\circ} \mathrm{C}$ restores the deep level spectrum.

Soon after this work, the wide research of the hydrogen neutralization of the electrically activity of radiation defects [108], thermal donors [21], and different fast diffusing impurities [109] in silicon was performed. In addition, it was revealed that acceptor [110] and then donor [111] dopants can be also neutralized by atomic hydrogen. In all the abovementioned cases, the defect and dopant neutralization was carried out at lower temperatures in atomic hydrogen, than in molecular one; and the restoration of the electrical activity can be observed after the following thermal annealing in vacuum. The performed research has shown that hydrogen can neutralize as donor as acceptor defects and dopants. Thus, hydrogen is an amphoteric impurity in silicon which can have various charges in dependence on the type of silicon conductivity [112].

In the case of the multivalent impurities, hydrogen can partially neutralize them, by decreasing the impurity charge state. For instance, for a double acceptor, hydrogen traps one electron on its donor level, by leaving one level in the forbidden gap. Usually, this level is shallower than the previously observed ones [26]. The example of such acceptor dopant in Si is Be.

Hydrogen ion implantation in silicon leads to the creation of a considerable number of narrow absorption lines in the transmission IR spectra in the optical range from 2300 to $1800 \mathrm{~cm}^{-1}$ [113]. Most of these peaks have been annealed at $300^{\circ} \mathrm{C}$. Only three lines $(2210,2167$, and $1961 \mathrm{~cm}^{-1}$ ) have been not annealed at $400{ }^{\circ} \mathrm{C}$. The same lines were also appeared in silicon grown by zone melting in the hydrogen ambient [23]. It was suggested [114] that the intensive thermally stabile IR lines at 2210 
and $1961 \mathrm{~cm}^{-1}$ are associated with: i) silicon located in the $T_{a}$ interstitial position and bound with four hydrogen atoms and ii) split interstitial bound with two hydrogen atoms, respectively. Thus, more thermally stabile hydrogen defects can be related to silicon interstitials.

In monocrystalline silicon saturated by hydrogen [113] and in implanted silicon treated by hydrogen plasma [115], $\mathrm{Si}-\mathrm{H}$ and $\mathrm{Si}=\mathrm{H}_{2}$ bonds have been observed. These bonds can be linked as with fully hydrogenated vacancy defects (such as $\mathrm{VH}_{4}$ or $\mathrm{V}_{2} \mathrm{H}_{6}$ ) as with partially dissociated ones. For instance, a partially dissociated divacancy possesses a silicon atom bound with two hydrogen atoms $\left(=\mathrm{Si}=\mathrm{H}_{2}\right)$. Performing the $a b$ initio density-functional calculations, it was theoretically shown that the even $\equiv \mathrm{Si}=\mathrm{H}_{2}$ metastabile configuration which has a local minimum on the energy surface can exist in crystalline silicon [116].

To find out the nature of the hydrogen passivation of different defects and impurities and their structure, a lot of quantum-mechanical calculations have been performed for different defect configurations [117-123]. It was demonstrated [117] that the hydrogen saturation of a vacancy or divacancy results in the defect level shift from the forbidden bond towards the valence zone and makes its to be electrically inactive. The hydrogen saturation of a vacancy-oxygen defect (A-center) in silicon leads to the creation of a shallower level in the silicon forbidden gap [118].

\subsection{RF plasma annealing of implanted defects in silicon}

On the basis of IR researches of a hydrogen effect on the radiation defect neutralization, it was suggested [113] that a divacancy decreases its dissociation energy by atomic hydrogen binding. This is caused by that, for the hydrogenated vacancy, the partially dissociated configuration is more energy-profitable, i.e.,

$$
\mathrm{V}_{2} \mathrm{H}_{6}+2 \mathrm{H} \rightarrow \mathrm{V}_{2} \mathrm{H}_{8} *+(2 \times 3-1.3=4.7 \mathrm{eV}) \text {. }
$$

That is an exothermic reaction. In expression (4), it is taken into account that, during the $\mathrm{Si}-\mathrm{H}$ bond creation, the energy of $3 \mathrm{eV}$ is released, and the partial vacancy dissociation requires $1.3 \mathrm{eV}$. In such a manner, hydrogen can decrease the annealing temperature of this defect. It was one from the first explanations of the hydrogenenhanced annealing of vacancy defects in silicon.

To determine the origin of the RF plasma annealing of radiation defects in the subsurface silicon layer, the number of investigations of implanted $\mathrm{SiO}_{2}-\mathrm{Si}$ structures treated by RF plasma has been performed [20, 28, 57, $124,125]$. The ion implantations by different ions and at various doses have been employed with the control of the surface layer damage, by using a large number of research methods.

Radiation defects in subsurface $p$ - and $n$-type silicon layers have been produced by boron [57], phosphorous [20], and arsenic [125] ion implantations through the $\mathrm{SiO}_{2}$ layer. In the case of the boron ion implantation, point defects are preferably produced, while, under the phosphorus and arsenic ion implantations, the disordered regions which have presumably the vacancy origin are created [126].

For the study of deep levels in the subsurface silicon layer of $\mathrm{SiO}_{2}-\mathrm{Si}$ structures, the thermally stimulated charge release (TSCR) method [127] was explored. This method is very useful for the study of electrically active centers in strongly damaged semiconductor layers of metal-insulator-semiconductor (MIS) structures. The performed researches for all kinds of the implanted structure (with doses near $1 \times 10^{12}$ ions $/ \mathrm{cm}^{2}$ ) after the RF plasma treatment revealed a decrease of the deep level concentration related to ion implanted defects by more than two orders of magnitude [28]. The example of such results is depicted in Fig. 21.

In work [20], it was observed that the RF plasma treatment from the front side of a structure was considerably more efficient than that from the back side (Figs. 21 and 22). The control experiments showed [44] that atomic hydrogen under the treatment from the back side of a structure was not observed in the subsurface silicon layer. The optimal regime of the plasma treatment corresponded to the thermal annealing in the nitrogen atmosphere at $750{ }^{\circ} \mathrm{C}$ (Fig. 22), therefore the annealing temperature at the RF plasma effect falls in by a factor of almost two. The following thermal annealing in vacuum at the temperature range from 300 to $500{ }^{\circ} \mathrm{C}$ gave no significant restoration of the majority of deep levels that testifies to the actual annealing during such plasma treatment but not to the neutralization.
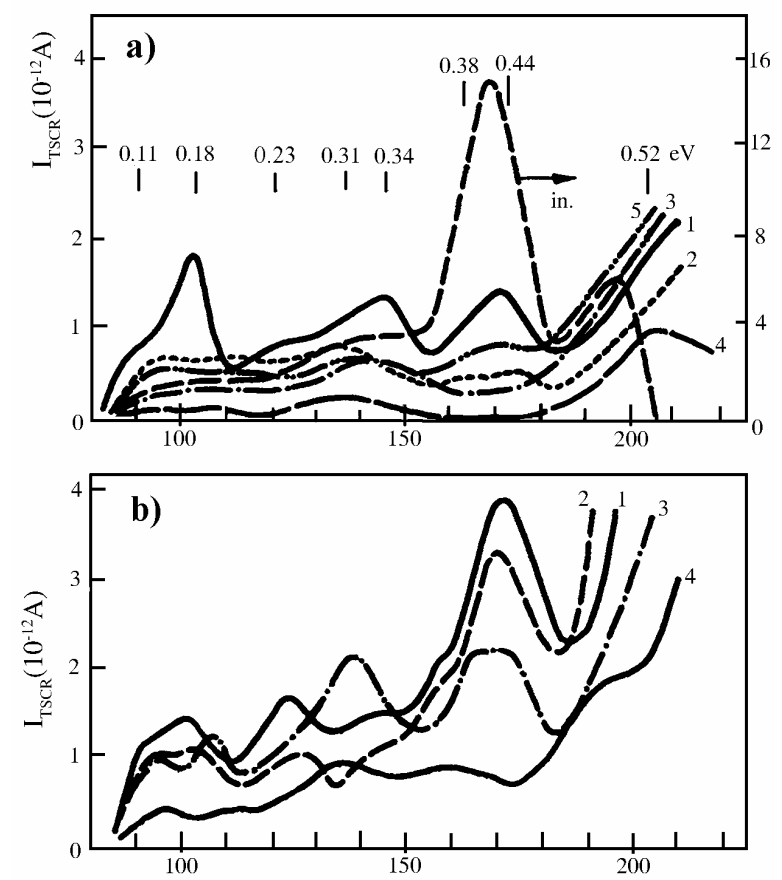

Fig. 21. TSCR spectra obtained on $\mathrm{Al}-\mathrm{SiO}_{2}-n \mathrm{Si}$ structures after the $\mathrm{P}^{+}$ion implantation $\left(D=1.5 \times 10^{12}\right.$ ions $\left./ \mathrm{cm}^{2}\right)$, treated with $\mathrm{RF}$ plasma discharge from front side (a) and back side (b) at various values of the treatment power density: $P=0.7$ (1); 0.9 (2); 1.6 (3); $2.2 \mathrm{~W} / \mathrm{cm}^{2}$ (4). The time of treatments is $15 \mathrm{~min}$ [28]. 


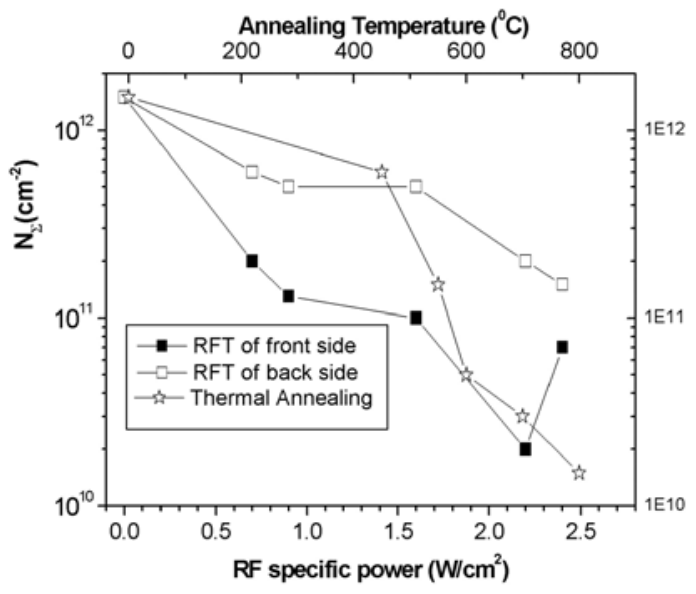

Fig. 22. Total concentration of deep levels, $N_{\Sigma}$, in the upper half of the Si band gap of implanted $\left(\mathrm{P}^{+}, D=1.5 \times 10^{12}\right.$ ions $\left./ \mathrm{cm}^{2}\right)$ $\mathrm{SiO}_{2}$-Si structures for various treatments as a function of the $\mathrm{RF}$ plasma power density and the annealing temperature $(t=$ $15 \mathrm{~min})$ [28].

It should be noted that the main deep levels observed by the TSCR technique (Fig. 21) can be associated with vacancy defects in silicon. For instance, the $E_{c}-0.18 \mathrm{eV}$ level is a vacancy-oxygen complex (Acenter), the $E_{c}-0.21 \mathrm{eV}$ and the $E_{c}-0.38 \mathrm{eV}$ levels are the divacancies in variuos charge states [128]. The $E_{c}-$ $0.44 \mathrm{eV}$ level was presumably related to a divacancy complex [128, 129]. Indeed, this level has a good correlation with an EPR $\mathrm{D}_{0}$-center observed in such structures [20]. The $\mathrm{D}_{0}$-center is well-known and is associated with a dangling Si-bond in amorphous silicon, so it can be related to large divacancy complexes which have to be produced during the ion implantation with heavy ions such as phosphorus and arsenic. Thus, we can conclude that most defects that can enhance the annealing under RF plasma treatment and are observed after the ion implantation, have the vacancy origin.

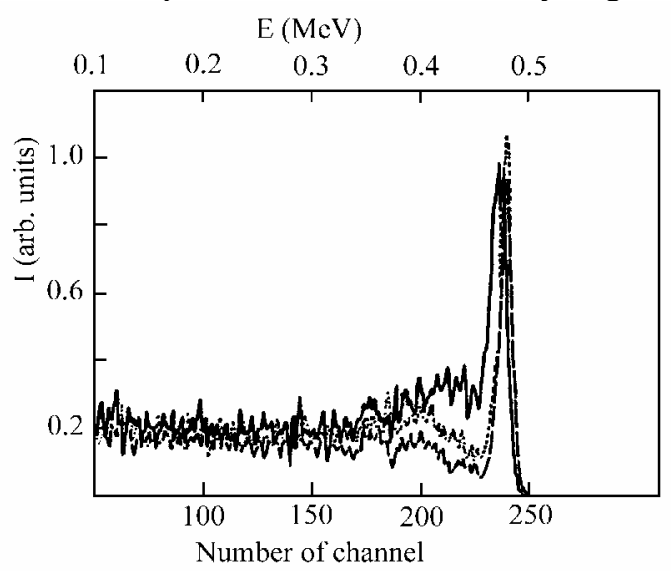

Fig. 23. Channeling RBS spectra of $120-\mathrm{keV} \mathrm{P}^{+}$implanted $\left(D=1 \cdot 10^{14}\right.$ ions $\left./ \mathrm{cm}^{2}\right)$ MOS structures after the thermal annealing and RF plasma treatment and the removal of $\mathrm{Al}$ and $\mathrm{SiO}_{2}$ layers. Solid curve - only implanted, dotted curve - implanted and thermal annealed at $450{ }^{\circ} \mathrm{C}$, dashed curve plasma-treated structures at the $2.2-\mathrm{W} / \mathrm{cm}^{2}$ power density [124].
The Rutherford backscattering (RBS) method in the channeling regime provided a direct evidence for the subsurface defect silicon layer ordering after the RF plasma treatment [124]. For this goal, the $\mathrm{SiO}_{2}-\mathrm{Si}$ structures have been implanted with phosphorus ions (implanted dose was $1 \times 10^{14}$ ions $/ \mathrm{cm}^{2}$ ) that gave rise to a strongly damaged subsurface silicon layer. Then the structures were subjected to either the RF plasma treatment in the optimal regime or the thermal annealing of the same duration (for comparison). It was revealed that the RF plasma treatment orders more effectively the subsurface layer than the thermal annealing at $450{ }^{\circ} \mathrm{C}$ (Fig. 23). In addition, the RF plasma effect decreases more effectively the paramagnetic $\mathrm{D}_{0}$-centers in comparison with the thermal annealing at $450{ }^{\circ} \mathrm{C}$ (Fig. 11), which suggests the enhanced plasma annealing of large damaged regions.

\subsection{RF plasma enhanced activation in the ion implanted silicon layer}

In work [20] together with researches of defects in $\mathrm{SiO}_{2}$ $\mathrm{Si}$ structures, the study of the implanted dopant activation after the RF plasma effect has been performed. For this goal, the capacitance-voltage $(C-V)$ free carrier profiling [129] and the low-temperature (4.2 K) photoluminescence (PL) of bound excitons [130] were used. The $C-V$ profiling showed the enhanced appearance of the electrical activity of dopants under the low-power RF plasma treatment (Fig. 24a). A distinctive peculiarity of this treatment was the appearance of free carrier profiles at first in the thin surface silicon layer and its distribution into silicon when the RF power was increased, that was quite different from the case of the
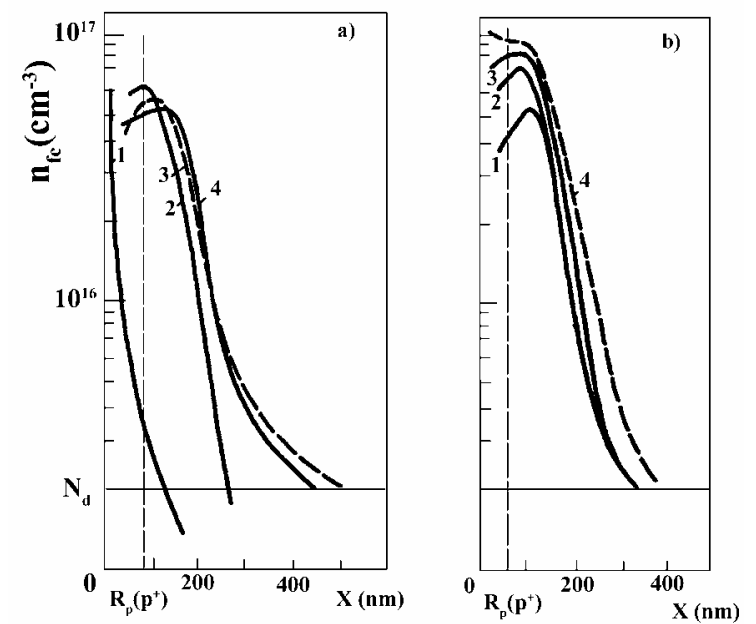

Fig. 24. Distribution of free carrier concentration, $n_{f c}$, in the silicon subsurface region in the implanted structures $\left(\mathrm{P}^{+}\right.$, $D=1.5 \times 10^{12}$ ions $/ \mathrm{cm}^{2}$ ) treated with RF plasma discharge from the front side (a) of the $\mathrm{Al}-\mathrm{SiO}_{2}-\mathrm{Si}$ structure at various power densities: $P=0.7$ (1); 0.9 (2); 1.6 (3); $2.2 \mathrm{~W} / \mathrm{cm}^{2}$ (4); and subjected to the thermal annealing (b) at various temperatures: $T_{a}=550(1) ; 600(2) ; 700(3) ; 800^{\circ} \mathrm{C}(4)(t=15 \mathrm{~min})$ ¡201. 
thermal annealing, for which the dopant profile was appeared in the whole implanted subsurface layer (Fig. 24b). The integral free carrier concentrations vs. both the RF power and the annealing temperature for these structures are shown in Fig. 25. The integral dopant activation by $1 \mathrm{~W} / \mathrm{cm}^{2} \mathrm{RF}$ plasma is similar to that under the thermal annealing at $650{ }^{\circ} \mathrm{C}$.

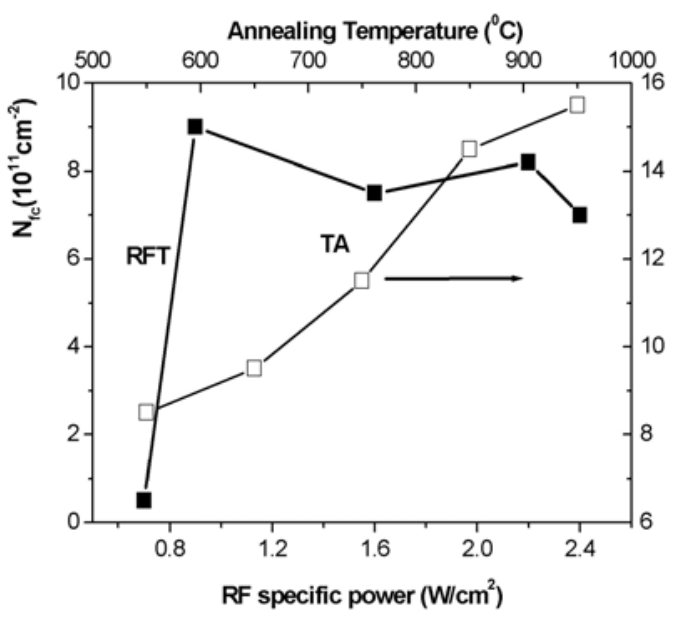

Fig. 25. Integral free carrier concentrations in the silicon subsurface layer in implanted $\mathrm{SiO}_{2}-\mathrm{Si}$ structures $\left(\mathrm{P}^{+}\right.$, $\left.D=1.5 \cdot 10^{12} \mathrm{ions} / \mathrm{cm}^{2}\right)$ as a function of the RF power density and the annealing temperature $(t=15 \mathrm{~min})$ [20].
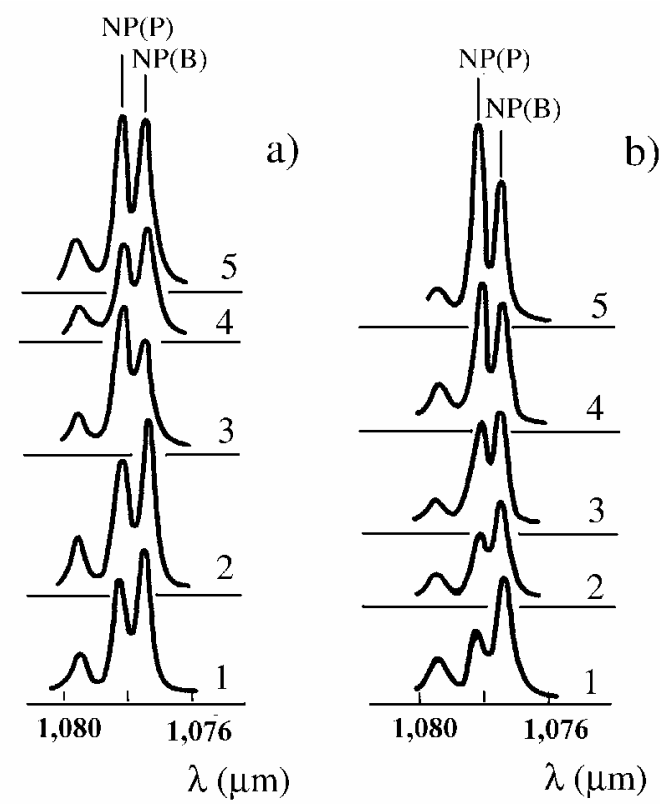

Fig. 26. PL spectra $\left(T_{m}=4.2 \mathrm{~K}\right)$ of bound exciton complexes in boron-doped and phosphorus-implanted $\mathrm{Si}$ : (a) after RF plasma treatment at various power densities $P=1.0$ (1); 1.3 (2); 1.6 (3); 2.0 (4); $2.3 \mathrm{~W} / \mathrm{cm}^{2}$ (5); (b) without annealing (1); after thermal annealing at various temperatures $T_{a}=300$ (2); 550 (3); 650 (4); $950{ }^{\circ} \mathrm{C}(5)$. Treatment time is $15 \mathrm{~min}$ [131].
The results of the $C-V$ profiling strongly depend on the concentration of defects compensating the dopant electrical activity. The concentration of these defects can fall considerably after the plasma treatment (as it was outlined in the previous part of this review). To find out explicitly whether there is the enhanced activation of an implanted dopant (in our case, phosphorus) during the plasma treatment, the technique based on the PL of bound excitons was applied to these samples $[15,131]$ (see Fig. 26). For obtaining the useful information from the PL spectra, the signal intensity of excitons related to phosphorus was normalized by the signal intensity of excitons related to free boron in a silicon wafer. Because of the hydrogen passivation of the boron dopant was not observed under the used plasma treatment, the boron concentration in the wafer can serve as the concentration standard during treatments. As seen from Fig. 27, the extent of phosphorus activation after the plasma treatment can cover up to $75 \%$ of the implanted phosphorus. However, the compensated defects existing in the implanted silicon layer do not allow one to reveal the total dopant concentration by the $C-V$ profiling experiments. Studying the PL of bound excitons for the samples treated by RF plasma from the front and back sides confirms the influence of nonthermal factors on the dopant activation [15].

The following experiments, using the combined treatments of $\mathrm{As}^{+}$ion implanted $\mathrm{SiO}_{2}-\mathrm{Si}$ structures, support the idea of the additional compensation defect annealing to reveal the total dopant activation after a plasma treatment [125]. The thermal annealing in the nitrogen atmosphere or the flash lamp annealing by using a halogen lamp with the following treatment in RF plasma gave rise to excellent activation results. Post metallization annealing with the following plasma treatment allowed one to activate near $75 \%$ of the implanted dopant that can be measured by the $C-V$ profiling method.

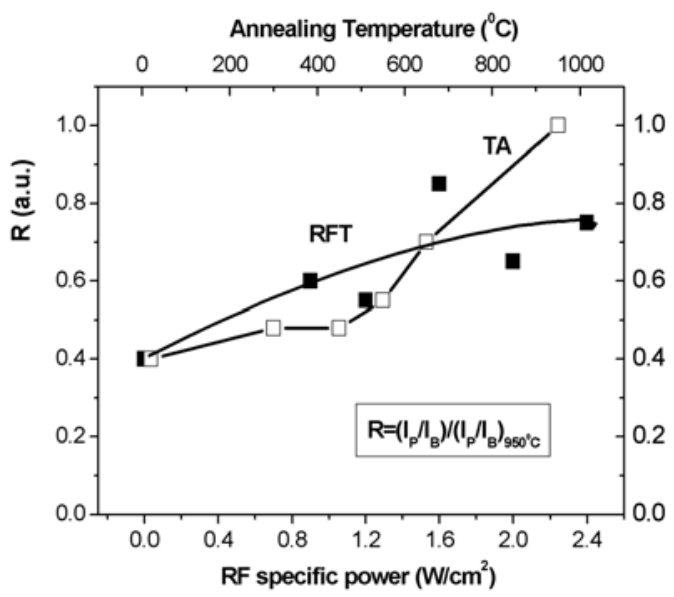

Fig. 27. Normalized intensity ratios, $R$, for boron-bound and phosphorus-bound excitons in boron-doped and phosphorusimplanted Si vs. the discharge power density and the annealing temperature [131]. 


\subsection{A model of enhanced hydrogen annealing of vacancy defects in silicon}

The analysis of the mutually supplementary experiments allows us to conclude that the RF plasma treatment results in both the enhanced annealing of radiation defects, most of which has the vacancy origin, and the enhanced activation of implanted dopants. On the basis of the obtained results in works $[20,28]$, a model of enhanced atomic hydrogen annealing of vacancy defects has been proposed. In this model, hydrogen plays the role of a catalyst of the defect reaction. In works [132-135], this model was supported by quantum-mechanical calculations and extended to the dopant activation process. The calculations have been performed on the basis of the SCF MO LCAO technique in the NDDO valence approach.

The model is determined by the following main positions: i) the trapping of a hydrogen atom by the vacancy leads to the substantial relaxation of the crystalline lattice near the vacancy, which results in an essential expansion of the inner vacancy region (see, for example, Fig. 28a, b); ii) the enlargement of the inner vacancy region reduces the potential barrier for a silicon interstitial or for a dopant impurity being built into the vacancy lattice site; iii) a silicon atom or an impurity are incorporated into the vacancy lattice site with the breaking of the Si-H bonds and the release of hydrogen (Fig. 28c).

Experimental data evidencing the substantial relaxation of the damaged silicon lattice and the amorphous silicon phase after the RF plasma treatment and after the hydrogen low-energetic ion bombardment have been obtained by the Raman scattering technique $[16,17]$ and by X-ray triple crystal diffractometry [136]. The theoretical evidence for this fact was first presented in work [137], and the extended calculations taking various hydrogen locations and vacancy charges into account have been presented in paper [132]. Some results of these calculations are shown in Table 2. As seen, the size of a vacancy after hydrogenation is considerably extended even more than that in the case of the ideal silicon lattice. In addition, in the case of a hydrogenated vacancy, the energy barrier height for the silicon interstitial incorporation into a vacant site essentially decreases (Fig. 29). A similar decrease is also observed for B, P, and As impurities (Table 3) [134]. The average decrease of the energy barrier is determined by a factor of 1.5 and depends on the vacancy charge and the interstitial diffusion direction. The estimation of the activation temperature decrease for the main implanted impurities demonstrates the temperature profit near $300^{\circ} \mathrm{C}$ [134], which is in a good agreement with the experimental results obtained on the samples treated by RF plasma [20] and on the samples subjected to the combined hydrogen and arsenic implantation [106].

The energy balance for the reaction of impurity incorporation (phosphorus, for example) into a vacant site of the hydrogenated vacancy has been shown to be positive, i.e., the reaction such as

$\mathrm{Si}-\mathrm{H}+\mathrm{P}_{i} \rightarrow \mathrm{Si}-\mathrm{P}+\mathrm{H}[(19.8-4.5) / 4]=3.83 \mathrm{eV}$ is exothermic [106]. Thus, one can expect the hydrogen separation from $\mathrm{Si}-\mathrm{H}-\mathrm{P}$ bond in the reaction region with the following trapping it by neighboring dangling bonds or the creation of interstitial molecules $\mathrm{H}_{2}$ [138] or $\mathrm{H}_{2}{ }^{*}$ [139]. If the defect is a complicated vacancy complex, the annealing of such a defect has to be carried out on the defect periphery, where hydrogen is located and the stresses are relaxed. Then the impurity incorporation will go to the center of a defect gradually abolishing it.

Table 2. Energy barrier heights for the diffusion of interstitial silicon atoms $(\Delta E)$ and displacements of the four atoms surrounding a vacancy $(\Delta R)$.

\begin{tabular}{|c|c|c|c|c|}
\hline $\begin{array}{c}\text { Path of a Si } \\
\text { atom }\end{array}$ & $\begin{array}{c}\Delta E\langle 111\rangle \\
(\mathrm{eV})\end{array}$ & $\begin{array}{c}\Delta E\langle 100\rangle \\
(\mathrm{eV})\end{array}$ & $\begin{array}{c}\Delta E\langle 110\rangle \\
(\mathrm{eV})\end{array}$ & $\begin{array}{c}\Delta R \\
(\AA)\end{array}$ \\
\hline $\begin{array}{c}\text { Leaves a site } \\
\text { without } \mathrm{H}\end{array}$ & 27.7 & 30.3 & 31.2 & 0 \\
\hline $\begin{array}{c}\text { Enter a vacancy } \\
\text { without } \mathrm{H}\end{array}$ & 9.2 & 11.7 & 12.4 & -0.15 \\
\hline $\begin{array}{c}\text { Enter a vacancy } \\
\text { with } \mathrm{H}_{0}\end{array}$ & $5.6(6.2)$ & $8.6(9.1)$ & $9.4(9.9)$ & $\begin{array}{c}0.21 \\
(0.20)\end{array}$ \\
\hline $\begin{array}{c}\text { Enter a vacancy } \\
\text { with } \mathrm{H}^{+}\end{array}$ & 5.1 & 8.9 & 8.9 & 0.25 \\
\hline
\end{tabular}

(The figures in parentheses are calculated for hydrogen located inside the vacancy.)

Table 3. Potential barrier heights $(\mathrm{eV})$ for the incorporation of different dopants into a vacancy site for hydrogen localized outside and inside (in parentheses) the vacancy.

\begin{tabular}{|c|c|c|c|c|c|c|c|c|c|}
\hline \multirow[b]{2}{*}{$\begin{array}{c}\text { State } \\
\text { of } \\
\text { vacancy }\end{array}$} & \multicolumn{3}{|c|}{ B } & \multicolumn{3}{|c|}{$\mathrm{P}$} & \multicolumn{3}{|c|}{ As } \\
\hline & $\widehat{\Xi}$ & $\stackrel{\widehat{̊}}{ٍ}$ & $\begin{array}{l}\widehat{\hat{O}} \\
\Xi\end{array}$ & $\widehat{\widehat{\Xi}}$ & $\stackrel{\widehat{\Xi}}{\varrho}$ & $\begin{array}{l}\widehat{\hat{O}} \\
\Xi\end{array}$ & $\widehat{\Xi}$ & $\stackrel{\widehat{\Xi}}{\approx}$ & $\begin{array}{l}\widehat{\hat{O}} \\
\Xi\end{array}$ \\
\hline V & 6.3 & 7.6 & 8.5 & 7.2 & 8.6 & 9.5 & 8.8 & 11.1 & 12.1 \\
\hline $\mathrm{VH}_{4}{ }^{0}$ & $\begin{array}{c}3.7 \\
(4.4)\end{array}$ & $\begin{array}{c}5.0 \\
(5.6)\end{array}$ & \begin{tabular}{|c|}
5.8 \\
$(6.4)$
\end{tabular} & \begin{tabular}{|c|}
4.5 \\
$(5.1)$
\end{tabular} & $\begin{array}{c}6.2 \\
(6.9)\end{array}$ & \begin{tabular}{|c}
6.9 \\
$(7.4)$
\end{tabular} & $\begin{array}{c}5.4 \\
(5.9)\end{array}$ & $\begin{array}{c}7.3 \\
(8.0)\end{array}$ & \begin{tabular}{|c|}
8.1 \\
$(8.6)$
\end{tabular} \\
\hline $\mathrm{VH}_{4}^{+}$ & 3.3 & 4.4 & 5.1 & 4.1 & 5.6 & 5.9 & 4.8 & 7.3 & 7.7 \\
\hline
\end{tabular}

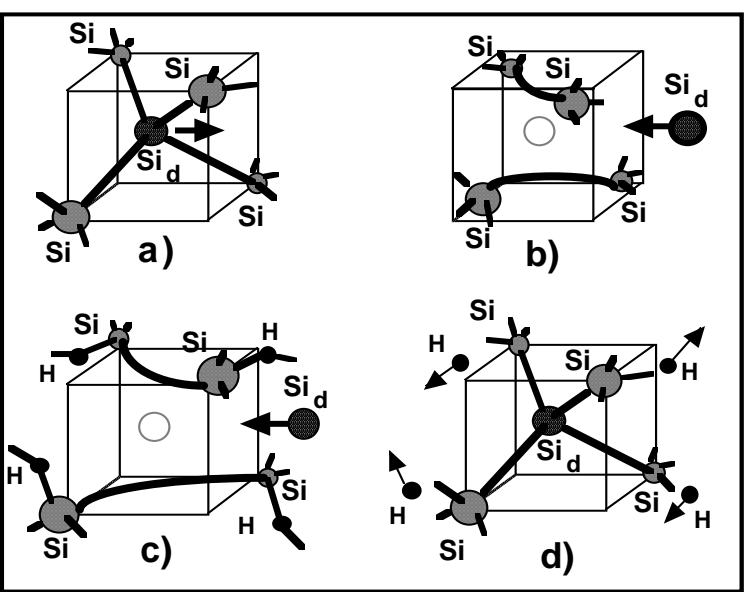

Fig. 28. Schematical illustration of the model of enhanced annihilation of Frenkel pairs with participation of atomic hydrogen: (a) ideal Si crystal; (b) interstitial Si moves towards a nonhydrogenated vacancy; (c) interstitial Si moves towards a hydrogenated vacancy; (d) hydrogen migrates towards other vacancies [132]. 


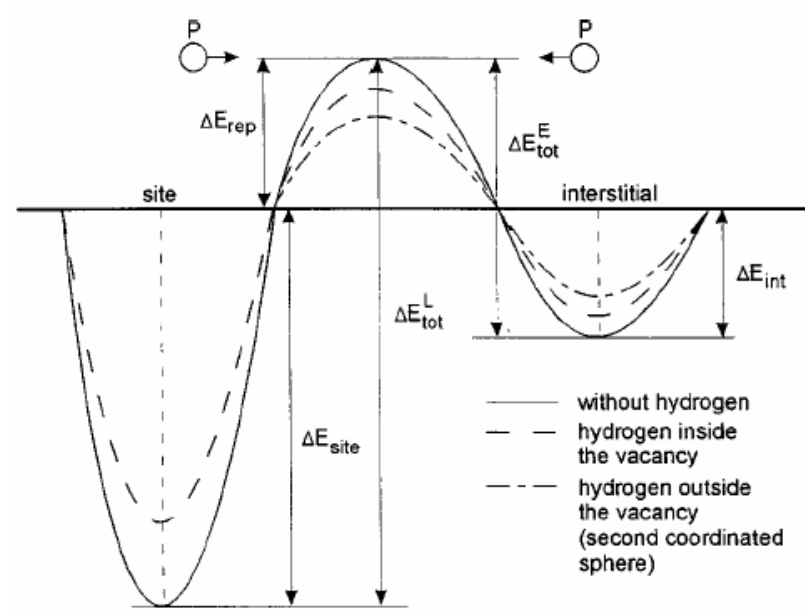

Fig. 29. Potential barriers for an impurity atom entering the vacancy region and exiting from the crystal site [133].

Thus, the proposed mechanism does not need a large amount of atomic hydrogen and can explain the enhanced annealing of a lot of vacancy defects and the enhanced activation of implanted dopants in silicon.

\section{RF plasma ordering of amorphous silicon layer}

Whereas the hydrogen plasma treatment in the case of a strongly disordered ion implanted silicon layer leads to the enhanced radiation defect annealing, no enhanced recrystallization is revealed in the case of the ionimplanted amorphized silicon layer. In work [124], the RBS study of amorphous subsurface silicon layers fabricated by the phosphorus ion implantation (dose was $1 \times 10^{15}$ ions $/ \mathrm{cm}^{2}$ ) has been performed. The total recrystallization of the amorphous layer after the thermal annealing at $550{ }^{\circ} \mathrm{C}$ and its absence after the RF plasma treatment with maximum power have been demonstrated.

To find out the structure of the subsurface silicon layer under such treatments, the Raman scattering technique has been employed [140]. The Raman spectrum of the implanted silicon is mainly determined by the amorphous phase with a small amount of microcrystalline inclusions (see Fig. 30). The RF plasma treatment results in an increase of the microcrystalline dimensions and a decrease of the root-mean-square bond-angle fluctuation, $\Delta \bar{\theta}$, in the amorphous part. The estimations have shown that, after phosphorus implantation, the dimensions of microcrystalline inclusions in the amorphous phase is $35 \AA$; after the thermal annealing at $500{ }^{\circ} \mathrm{C}$, they do not exceed $65 \AA$; while, after the RF plasma treatment (power is $2.0 \mathrm{~W} / \mathrm{cm}^{2}$ ), the dimensions of microcrystalline inclusions increase up to $90 \AA$.
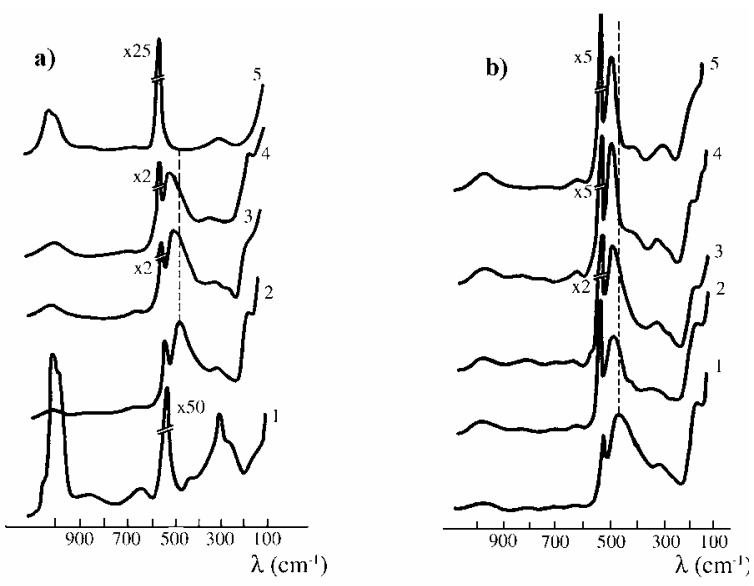

Fig. 30. Raman spectra of $\mathrm{Si}$ implanted with $\mathrm{P}^{+}$ions $\left(D=1 \times 10^{15}\right.$ ions $\left./ \mathrm{cm}^{2}\right)$ and subjected (a) to the treatment with thermal annealing at various temperatures (initial unimplanted sample (1), $350{ }^{\circ} \mathrm{C}(2), 450$ (3), 525 (4) and 950 (5)) and (b) different RF plasma power densities (initial implanted sample (1), $0.5 \mathrm{~W} / \mathrm{cm}^{2}$ (2), 0.9 (3), 1.2 (4), $2.0(5))$ [16].

In Fig. $31, \Delta \bar{\theta}$ as a function of the thermal annealing temperature and the specific power of RF plasma are presented. The parameter, $\Delta \bar{\theta}$, is determined by structural peculiarities of the amorphous phase, and the structure of amorphous silicon is stable if $\Delta \bar{\theta}>6.6^{\circ}$, while the structures with intermediate values $\left(0<\Delta \bar{\theta}<6.6^{\circ}\right)$ do not exist [140]. During a thermal annealing of the implanted silicon, $\Delta \bar{\theta}$ changes from $13.5^{\circ}$ to $0^{\circ}$ in the narrow temperature interval from 500 to $525^{\circ} \mathrm{C}$. During the RF plasma treatment, the full relaxation of the $\mathrm{Si}$ amorphous structure is observed.

In work [20], the Raman study of an amorphous silicon layer has been performed together with EPR measurements. The full correlation of $\mathrm{D}_{0}$-EPR center concentration dependences as a function of the RF plasma specific power and the thermal annealing temperature with the same dependences of $\Delta \bar{\theta}$ has been observed (Fig. 31 a, b, c, d). From these results, it becomes clear that a sharp decrease of the $\mathrm{D}_{0}$-center concentration at temperatures above $500{ }^{\circ} \mathrm{C}$ related to the amorphous layer recrystallization and the relaxation of mechanical stresses in the amorphous layer under the RF plasma treatment is associated with a decrease of the number of dangling bonds in the amorphous Si phase. In work [20], it was suggested that the last effect is related to the hydrogenation of the amorphous layer and the creation of Si-H bonds, which leads to a decrease of the paramagnetic activity of defects in this layer and to the amorphous Si network relaxation. 

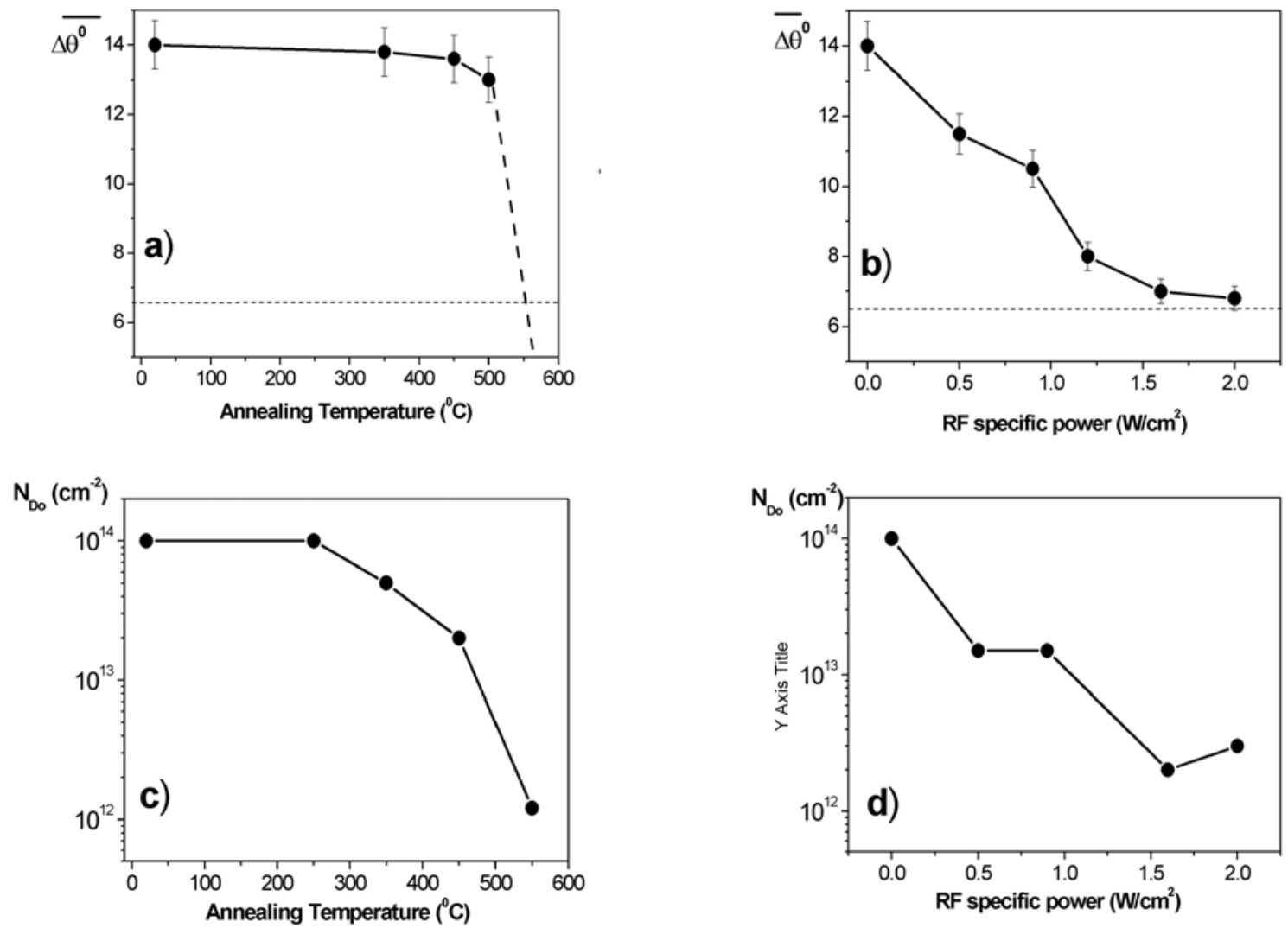

Fig. 31. The change in $\Delta \bar{\theta}(\mathrm{a}, \mathrm{b})$ and in the $\mathrm{D}_{0}$-center concentration (c, d) in $\mathrm{P}^{+}$implanted $\left(D=1 \times 10^{15}\right.$ ions/cm $\left.{ }^{2}\right)$ Si subjected to the thermal annealing (a, c) and treated with a RF plasma discharge (b, d) and [16].

\section{Conclusions}

The combination of the hydrogenation of a material with an intensive defect overcharging and the enhanced temperature (factors that exist at the RF plasma effect) leads to the effective transformation of the silicon dioxide structure, dielectric-semiconductor interface, and subsurface disturbed semiconductor layer. In this connection, the hydrogen plasma treatment can be successfully employed on the final step of the fabrication of silicon thin-film CMOS devices instead of the traditional post metallization annealing or the rapid thermal annealing.

One of the important consequences of the hydrogen plasma treatment is the relaxation of a disordering and the amorphous structure of semiconductor and dielectric materials. Taking this phenomenon into account allows one in a lot of cases to understand the processes running in semiconductors under plasma treatment or under hydrogenation. For example, the enhanced radiation hardness of hydrogenated silicon [141, 142] can be explained by an increase of the silicon interstitial trapping by hydrogenated vacancies during the creation of Frenkel pairs; the enhanced thermal donor creation after the hydrogen plasma treatment of silicon can be associated with the easier oxygen incorporation in vacant sites in a hydrogenated material, which could be a precursor for the thermal donor creation in the future.

Hydrogen plasma treatment is very attractive for amorphous materials containing semiconductor crystalline nanoinclusions. This allows us to order the amorphous matrix and to anneal dangling bonds in the nanocrystal/amorphous matrix interface, which has to increase the light-emitting properties of materials and to improve the durability of the devices employing these materials.

Hydrogen plasma treatment can be perspective both for silicon and for wide-band gap semiconductor materials such as $\mathrm{A}^{\mathrm{III}} \mathrm{B}$ which cannot endure a heating to high temperatures, but the recombination-enhanced processes effectively appeared in them [82]. This can be related mainly to thin subsurface layers of such semiconductors and multilayer semiconductor structures on that basis [143]. The combination of the hydrogen surface treatment of such materials with the plasmachemical deposition of an insulator on their surface would allow one to obtain MIS structures without Fermi level pinning on the insulator-semiconductor interface. 


\section{References}

1. M.A. Foad, D. Jennings, Formation of ultrashallow junction by ion implantation and RTA // Solid State Technol. 12, p. $43-54$ (1998).

2. T.P. Ma, W.H.-L. Ma, Effect of RF annealing on excess charge centers in MIS dielectrics // IEEE J. Solid State Circ. SC-13, N 4, p. 445 (1978).

3. S.D.S. Malhi, Characteristics and three-dimensional integration of MOSFET's in small grain LPCVD polycrystalline silicon // IEEE Trans. Electron. Devices, ED-32, N 2, p. 252 (1985).

4. Y.S. Tsuo, J.B. Milstein, Recent results on hydrogen passivation of silicon sheet solar cells // J. Appl. Phys. 57 (12), p. 5523 (1985).

5. A. Mimura, N. Konishi, K. Ono, J. Ohwada, Y. Hosokawa, Y.A. Ono, T. Suzuki, K. Miyata, H. Kawakami, High-performance low-temperature polySi n-channel TFT's for LCD // IEEE Trans. Electron. Dev. 36 (2), p. 351 (1989).

6. D. Pribat, F. Plais, P. Legagneux, T. Kretz, R. Stroh, O. Huet, C. Walaine, M. Magis, N. Jiang, M.C. Hugon, B. Agius, Low temperature polysilicon TFTs for active matrix LCDs // Rev. Technique Thomson-CSF, 26 (1), p. 73 (1994).

7. J.M. Hwang, D.K. Schroder, W.J. Biter, Deep levels introduced into silicon during hydrogen plasma annealing // J. Appl. Phys. 57 (12), p. 5275 (1985).

8. T.P. Ma, W.H.-L. Ma, The effect of RF annealing upon electron-beam irradiated MIS structures // Solid State Electron. 22 (4), p. 663 (1979).

9. V.S. Lysenko, T.N. Sytenko, Q.V. Snitko, V.I. Zimenko, A.N. Nazarov, I.N. Osiyuk, T.E. Rudenko, I.P. Tyagulskii, Interrelation between surface states and transition layer defects in $\mathrm{Si}_{-} \mathrm{SiO}_{2}$ structures // Solid State Communs 57 (3), p. 171 (1986).

10. M.Ya. Valakh, V.A. Yukhimchuk, V.Ya. Bratus', A.A. Konchits, P.L.F. Hemment, T. Komoda, Optical and electron paramagnetic resonance study of light-emitting $\mathrm{Si}^{+}$ion implanted silicon dioxide layers // J. Appl. Phys. 85 (1), p. 168-173 (1999).

11. I.Z. Indutnyy, V.S. Lysenko, I.Yu. Maidanchuk, V.I. Min'ko, A.N. Nazarov, A.S. Tkachenko, P.E. Shepeliavyi, V.A. Dan'ko, Effect of chemical and radio-frequency plasma treatment on photoluminescence of $\mathrm{SiO}_{\mathrm{x}}$ films // Semiconductor Physics, Quantum Electronics \& Optoelectronics 9 (1), p. 9-13 (2006).

12. V.P. Kunets, N.R. Kulish, V.V. Strelchuk, A.N. Nazarov, A.S. Tkachenko, V.S. Lysenko, M.P. Lisitsa, CdSSe quantum dots: effect of the hydrogen RF plasma treatment on exciton luminescence // Physica E 22, p. 804-807 (2004).

13. J.L. Benton, C.J. Doherty, S.D. Ferris, D.L. Flamm, L.C. Kimerling, H.L. Leamy, Hydrogen passivation of point defects in silicon // Appl. Phys. Lett. 36 (8), p. 670 (1980)
14. V.S. Lysenko, M.M. Lokshin, A.N. Nazarov, T.E. Rudenko, A.S. Tkachenko, Radio-frequency annealing of defects in implanted MIS-structures // Sov. Techn. Phys. Lett. 9 (7), p. 343 (1983).

15. M.Ya. Valakh, V.S. Lysenko, A.N. Nazarov, G.Yu. Rudko, A.S. Tkachenko, N.I. Shakhraychuk, Enhanced activation of implanted phosphorus in silicon under of plasma treatment // Nucl. Instr. and Meth. Phys. Res. B 44, p. 146-148 (1989).

16. V.V. Artamonov, V.S. Lysenko, A.N. Nazarov, B.D. Nichiporuk, V.V. Streltchuk, M.Ya. Valakh, Radio-frequency plasma treatment and thermal annealing in implanted Si: Raman study // Phys. status solidi (a) 120 (2), p. 475 (1990).

17. V.V. Artamonov, V.S. Lysenko, A.N. Nazarov, V.V. Streltchuk, M.Ya. Valakh, I.M. Zaritskii, Relaxation of amorphous structure of implanted Si under RF plasma treatment: Raman and EPR study // Semicond. Sci. Technol. 6 (1), p. 1 (1990).

18. T.P. Ma, M.R. Chin, RF annealing mechanisms in metal-oxide-semiconductor structures - an experimental simulation // J. Appl. Phys. 51 (10), p. 5458 (1980).

19. M.R. Chin, T.P. Ma, Voltage and frequency dependence of simulated plasma annealing in metal$\mathrm{SiO}_{2}-\mathrm{Si}$ strucrures // Appl. Phys. Lett. 40 (6), p. 490 (1982).

20. V.S. Lysenko, A.N. Nazarov, S.A. Valiev, I.M. Zaritskii, T.E. Rudenko, A.S. Tkachenko, EPR and TSCR investigations of implanted $\mathrm{Al}-\mathrm{SiO}_{2}-\mathrm{Si}$ systems treated with RF plasma discharge // Phys. status solidi (a) 113 (2), p. 655 (1989).

21. A. Chantre, S.J. Pearton, L.C. Kimerling, K.D. Cummings, W.L. Dantremond-Smith, Interaction of hydrogen and thermal donor defects in silicon // Appl. Phys. Lett. 50 (9), p. 513 (1987).

22. J.I. Pankov, Hydrogen neutralization of defects in silicon // Cryst. Latt. Def. and Amorph. Mat. 11, p. 203 (1985).

23. S.J. Pearton, J.W. Corbett, T.S. Shi, Hydrogen in crystalline semiconductors // Appl. Phys. A 43 (3), p. 153 (1987).

24. M. Capizzi, A. Mittiga, Hydrogen in silicon: diffusion and shallow impurity deactivation // Physica B 146 (1), p. 19 (1987).

25. J. Chavallier, M. Aucoutarier, Hydrogen in crystalline semiconductors // Ann. Rev. Mater. Sci. 18, p. 219 (1988).

26. E.E. Heller, Hydrogen in crystalline semiconductors // Semicond. Sci. Technol. 6 (2), p. 73 (1991).

27. R. Jones, B.J. Coomer, J.P. Goss, B. Hourahine, A. Resende, The interaction of hydrogen with deep level defects in silicon // Solid State Phenomena 71, p. 173-249 (2000).

28. V.S. Lysenko, A.N. Nazarov, M.Ya. Valakh, Annealing and ordering of Si ion-implanted surface layers by RF plasma discharge, In: Ion Implantation and Ion Beam Equipment, ed. by D.S. Kar- 
puzov, I.V. Katardjiev, S.S. Todorov. World Sci., Singapore, 1991, p. 216.

29. S.M. Myers, M.I. Baskes, H.M. Birnbaum, J.W. Corbett, G.G. DeLeo, S.K. Estreicher, E.E. Heller, P. Jena, N.M. Johnson, R. Kirchheim, S.J. Pearton, M.J. Stavola, Hydrogen interactions with defects in crystalline solids // Rev. Mod. Phys. 64 (2), p. 559 (1992).

30. S.J. Pearton, J.W. Corbett, M.J. Stavola, Hydrogen in Crystalline Semiconductors. Springer, Berlin, 1992.

31. Proc. of 20th International Conference on the Physics of Semiconductors, Thessaloniki, Greece, 1990.

32. Proc. of 6th Trieste Semiconductor Symposium "Hydrogen in Semiconductors. Bulk and Surface Properties" // Physica B 170 (3) (1991).

33. Defect and Impurity Engineered Semiconductors and Devices, Eds. S. Ashok, J. Chevallier, K. Sumino, B.L. Sopori and W. Gotz, MRS Symp. // Proc. 378, MRS Spring Meeting, San Francisco, CA, 1995.

34. Hydrogen in Semiconductors and Metals, Eds. N.H. Nickel, W.B. Jackson, R.C. Bowman and R.G. Leisure, MRS Symp. // Proc. 513, MRS Spring Meeting, San Francisco, CA, 1998.

35. A. Szekeres, S.S. Simeonov, E. Kafedjiiska, RF plasma influence on shallow and deep levels in crystalline silicon // Physica B 170 (3), p. 231-234 (1991).

36. N.M. Johnson, Neutralization of donor dopants and formation of hydrogen induced defects in n-type silicon // Semiconductor and Semimetal 34, ed. by J.I. Pankov and N.M. Johnson, Ch. 7, p. 113, Academic Press, New York, 1991.

37. D.V. McGaughan, R.A. Kushner, Degradation of oxide films due to radiation effects in exposure to plasma in sputter deposition and backsputtering // Proc. IEEE 62 (9), p. 1236 (1974).

38. VLSI Technology, ed. by S.M. Sze. McGraw-Hill, New York, 1983.

39. S. Alexandrova, A. Szekeres, The effect of RF plasma upon thermal $\mathrm{SiO}_{2} / /$ Bulg. J. Phys. 11 (5), p. 499 (1984).

40. A.N. Nazarov, V.S. Lysenko, A.S. Tkachenko, I.V. Gavgiljuk, M.I. Gorodyskii, S. Mikhaylov, V.A. Skryshevskii, Modification of $\mathrm{SiO}_{2}$ films of $\mathrm{SiO}_{2}-\mathrm{Si}$ structures under plasma treatment // Proc. of the 9th All-Union conference "Particle interactions with solid state”, Moscow, 1989, p. 44 (in Russian).

41. A.N. Nazarov, V.I. Kilchitska, I.P. Barchuk, A.S. Tkachenko, S. Ashok, Radio frequency plasma annealing of positive charge generated by Fowler-Nordheim electron injection in buried oxide in silicon // J. Vac. Sci. Technol. B 18 (3), p. 12541261 (2000).
42. G.S. Oehrlein, Reactive-ion etching // Physics Today, N 10, p. 26 (1986).

43. O.O. Awadelkarim, P.I. Mikulan, T. Gu, R.A. Ditizio, S.J. Fonash, Hydrogen penetration, Si defect generation abd there interaction during $\mathrm{CHF}_{3} / \mathrm{O}_{2}$ contact etching // IEEE Electron. Dev. Lett. 15 (3), p. 85 (1994).

44. V.S. Lysenko, A.N. Nazarov, G.A. Naumovets, V.B. Popov, A.S. Tkachenko, Manifestation of hydrogen in $\mathrm{Al}-\mathrm{SiO}_{2}-\mathrm{Si}$ structures subjected to a RF plasma annealing // Phys. status solidi (a) 112 (1), p. K9 (1989).

45. C. Kiseilowski-Kemmerich, W. Beger, Hydrogen desorption from crystalline silicon and its modification due to the presence of dislocations // J. Appl. Phys. 66 (2), p. 552 (1989).

46. A.D. Marwick and D.R. Young, Measurements of hydrogen in metal-oxide-semiconductor structures using nuclear reaction profilling // J. Appl. Phys. 63(7), p. 2291 (1988).

47. M.A. Biere, D.A. Braunig, A quantitative investigation of hydrogen in metal-oxide-silicon system using NRA // IEEE Trans. Nucl. Sci., NS37 (6), p. 1658 (1990).

48. J. Krauser, A. Weidinger, D. Braunig, Hydrogen distribution at the oxide/silicon interface reflecting the microscopic structure of the near-interface region, In: The Physics and Chemistry of $\mathrm{SiO}_{2}$ and $\mathrm{Si}_{-} \mathrm{SiO}_{2}$ Interface-3, Eds. H.Z. Massoud, E.H. Poindexter and C.R. Helms. ECS Inc., NJ, 1996, V.96-1, p. 184.

49. A.G. Revesz, The role of hydrogen in $\mathrm{SiO}_{2}$ films on silicon // J. Electrochem. Soc. 126 (1), p. 122 (1979).

50. R. Gale, F.J. Feigl, C.W. Magee, D.R. Yung, Hydrogen migration under avalanch injection of electrons in Si metal-oxide-semiconductor capacitors // J. Appl. Phys. 54 (12), p. 6938 (1983).

51. C.T. Sah, J.Y.-C. Sun, J.J.-T. Tzou, Study of the atomic models of three donor-like defects in silicon metal-oxide-semiconductor structures from their gate material and process dependencies // J. Appl. Phys. 55(6), p. 1525 (1984).

52. C.T. Sah, S.C.S. Pan, S.C.H. Heu, Hydrogenation and annealing kinetics of group-3 acceptors in oxidized silicon // J. Appl. Phys. 57(12), p. 5148 (1985).

53. S. Dadgar, C.C.-H. Hsu, S.C-.S. Pan, C.T. Sah, Hydrogenation and annealing kinetics in boronand aluminum-doped silicon // J. Appl. Phys. 60(4), p. 1422 (1986).

54. D. Ballutaud, A. Boutry-Forveille, A. Nazarov, Hydrogen thermal stability in buried oxides of SOI structures // Microelectronics Engineering 48, p. 359-362 (1999).

55. A. Boutry-Forveille, A. Nazarov, D. Ballutaud, Hydrogen as a diagnostic tool in analyzing SOI structures, In: Perspectives, Science and Techno- 
logies for Novel Silicon-On-Insulator Devices, Eds. P.L.F. Hemment et al., Kluwer, Dordrecht, 2000, p. $179-186$.

56. A. Nazarov, Hydrogen and high-temperature charge instability of SOI structures and MOSFETs, in Science and Technology of Semiconductor-OnInsulator Structures and Devices Operating, In: A Harsh Environment, ed. by D. Flandre et al. Kluwer, Dordrecht, 2005, p. 121-132.

57. V.S. Lysenko, M.M. Lokshin, A.N. Nazarov, T.E. Rudenko, RF plasma annealing of implanted MIS structures // Phys. status solidi (a) 88 (2), p. 705 (1985).

58. S. Alexandrova, A. Szeceres, W. Fussel, H. Fleatner, RF plasma annealing effect at the wet oxidized $\mathrm{SiO}_{2} / \mathrm{Si}$ interface // Phys. status solidi (a) 98 (2), p. 645 (1986).

59. P.L. Castro, B.E. Deal, Low-temperature reduction of fast surface states associated with thermally oxidized silicon // J. Electrochem. Soc. 118 (2), p. 280 (1971).

60. T.W. Hickmott, Annealing of surface states in polycrystalline-silicon-gate capacitors // J. Appl. Phys. 48 (2), p. 723 (1977).

61. M.L. Reed, J.D. Plummer, Chemistry of $\mathrm{Si}_{-} \mathrm{SiO}_{2}$ interface trap annealing // J. Appl. Phys. 63 (12), p. 5776 (1988).

62. K.L. Brower, S.M. Myers, Chemical kinetics of hydrogen and (111) $\mathrm{Si}_{-} \mathrm{SiO}_{2}$ interface defects // Appl. Phys. Lett. 57 (2), p. 162 (1990).

63. E. Cartier, J.H. Stathis and D.A. Buchanan, Passivation and depassivation of silicon dangling bonds at the $\mathrm{Si} / \mathrm{SiO}_{2}$ interface by atomic hydrogen // Appl. Phys. Lett. 63 (11), p. 1510 (1993).

64. S. Alexandrova, A. Szekeres, Charged defects in wet $\mathrm{SiO}_{2}$-Si structure modified by $\mathrm{RF}$ oxygen plasma treatment // Phys. status solidi (a) 171 (2), p. 487 (1999).

65. V.S. Lysenko, T.N. Sytenko, V.I. Zimenko, O.V. Snitko, Investigation of traps in the transition region of $\mathrm{Si}_{-} \mathrm{SiO}_{2}$ structures of cryogenic temperature // Phys. status solidi (a) 71 (2), p. 619 (1982).

66. R.B. Lauglin, J.D. Joannopoulos, C.A. Murray, K.J. Herhnett, T.J. Greytak, Intrinsic surface phonon in porous glass // Phys. Rev. Lett. 40 (7), p. 461 (1978).

67. E.H. Nicollian, J.R. Brews, MOS Physics and Technology. Wiley, New York, 1982.

68. A.N. Nazarov, V.S. Lysenko, S.N. Mikhaylov, A.S. Tkachenko, M.I. Pavlyuk, A.N. Molostvov and V.I. Kilchitskaya, RF plasma treatment effect on the charge transportation and accumulation in oxide silicon of Al-polySi-SiO $2-\mathrm{Si}$ structures // Mikroelektronika 22 (6), p. 15 (1993) (in Russian).

69. J. Nissan-Cohen, The effect of hydrogen on hot carrier and radiation immunity of MOS devices // Appl. Surf. Sci. 39 (1), p. 511 (1989).
70. J. Bos, M. Hendriks, Plasma-induced fixed oxide charge // J. Appl. Phys. 66 (3), p. 1244 (1989).

71. V.S. Lysenko, A.N. Nazarov, I.N. Osiyuk, V.I. Turchanikov, Transformation in $\mathrm{Si}_{-} \mathrm{SiO}_{2}-\mathrm{Al}$ structures under RF plasma treatment // Appl. Surf. Sci. 39 (1), p. 388 (1989).

72. A.N. Nazarov, J.N. Vovk, I.N. Osiyuk, A.S. Tkachenko, I.P. Tyagulskii, V.S. Lysenko, T. Gebel, L. Rebohle, W. Skorupa, R.A. Yankov, The effect of radio-frequency plasma treatment on the electroluminescent properties of violet lightemitting germanium implanted metal-oxidesemiconductor structures // Mater. Sci. and Eng. B 124-125, p. 458-461(2005).

73. A.N. Nazarov, W. Skorupa, Ja.N. Vovk, I.N. Osiyuk, A.S. Tkachenko, I.P. Tyagulskii, V.S. Lysenko, T. Gebel, L. Rebohle, R.A. Yankov, T.M. Nazarova, Modification of the electroluminescence and charge trapping in germanium implanted metal oxide silicon light emitting diodes with plasma treatment // Semiconductor Physics, Quantum Electronics \& Optoelectronics 8 (1), p. 90-94 (2005).

74. G.A. Scoggan, T.P. Ma, Effect of electron-beam radiation on MOS structures as influenced by silicon dopant // J. Appl. Phys. 48 (1), p. 294 (1977).

75. E.H. Nicollian, J.R. Brews, MOS Physics and Technology. Wiley, New York, 1982.

76. R.A. Weeks, Paramagnetic spectra of $\mathrm{E}_{2}$ centers in crystalline silica // Phys. Rev. 130(2), p 570 (1963).

77. P.J. Caplan, J.N. Helbert, B.E. Wagner, E.H. Poindexter, Paramagnetic defects in silicon/silicon dioxide systems // Surf. Sci. 54 (1), p. 33 (1976).

78. P.M. Lenahan, W.L. Warren, P.V. Dressendorfer, R.E. Mikawa, Generation of paramagnetic point defect in silicon dioxide films on silicon through electron injection and exposure to ionizing radiation // Zeitschrift Phys. Chem. Nene Folge, Bd151, S. 235 (1987).

79. J.P. Colinge, Silicon-on-Insulator Technology: Materials to VLSI. Kluwer, Dordrecht, 1991.

80. A.N. Nazarov, Problems of radiation hardness of SOI structures and devices, In: Physical and Technical Problems of SOI structures and Devices, ed. by J.P. Colinge et al. Kluwer, Dordrecht, 1995, p. 217-239.

81. A.N. Nazarov, V.I. Kilchytska, Y. Houk, D. Ballutaud, Mechanisms of positive charge generation in buried oxide of UNIBOND and separation by implanted oxygen silicon-on-insulator structures during high-field electron injection // J. Appl. Phys. 94 (3), p. 1823-1832 (2003).

82. L.C. Kimmerling, Recombination enhanced defect reactions // Solid State Electron. 21 (11/12), p. 1391 (1978).

83. T. Takagahara, K. Takeda, Theory of the quantum comfinement effect on exciton in quantum dots of 
indirect-gap materials // Phys. Rev. B 46 (23), p. 15578-15581 (1992).

84. D. Kovalev, H. Heckler, G. Polisski, F. Koch, Optical properties of Si nanocrystals // Phys. status solidi (b) 215 (2), p. 871-931 (1999).

85. V.A. Dan'ko, I.Z. Indutnyi, V.S. Lysenko, I.Yu. Maidanchuk, V.I. Min'ko, A.N. Nazarov, A.S. Tkachenko, P.E. Shepelyavyi, Kinetics of structural and phase transformations in thin $\mathrm{SiO}_{x}$ films in the course of a rapid thermal annealing // Semiconductors 39 (10), p. 1197-1203 (2005).

86. T. Komoda, J.P. Kelly, R.M. Gwilliam, P.L.F. Hemment, B.J. Sealy, Effect of the gas ambient on the intensity of the visible photoluminescence from $\mathrm{Si}$ microcrystallites in a $\mathrm{SiO}_{2}$ matrix formed by ion implantation // Nucl. Instrum. Meth. Phys. Res. B 112, p. 219 (1996).

87. I.P. Lisovskii, V.G. Litovchenko, V.B. Lozinskii, Effect of UV annealing of radiation damage in $\mathrm{SiO}_{2}$ films // Appl. Surf. Sci. 86, p. 299 (1995).

88. V.P. Kunets, N.R. Kulish, V.V. Strelchuk, A.N. Nazarov, A.S. Tkachenko, V.S. Lysenko, M.P. Lisitsa, Enhancement of CdSSe QD exciton luminescence efficiency by hydrogen RF plasma treatment // Semiconductor Physics, Quantum Electronic \& Optoelectronics 6 (2), p. 169-171 (2003).

89. L. Rebohle, J. von Borany, H. Fröb, W. Skorupa, Blue photo- and electroluminescence of silicon dioxide layers ion-implanted with group IV elements // Appl. Phys. B 70, p. 1-21 (2000).

90. A.N. Nazarov, I.N. Osiyuk, V.S. Lysenko, T. Gebel, L. Rebohle, W. Skorupa, Charge trapping and degradation in $\mathrm{Ge}^{+}$ion implanted $\mathrm{SiO}_{2}$ layer during high-field electron injection // Microelectronics Reliability 42, p. 1461-1464 (2002).

91. A.N. Nazarov, T. Gebel, L. Rebohle, W. Skorupa, I.N. Osiyuk, V.S. Lysenko, Trapping of negative and positive charges in Ge ion implanted silicon dioxide layers subjected to high-field electron injection // J. Appl. Phys. 94 (7), p. 4440-4448 (2003).

92. W. Skorupa, A. Nazarov, R.A. Yankov, T. Gebel, L. Rebohle, Verfahren zur Behandlung Siliziumbasierter Lichtemitter // Deutsche Patentanmeldung DE 10313727.0 (2003).

93. A.N. Nazarov, I.N. Osiyuk, I.P. Tyagulskii, V.N. Torbin, T.M. Nazarova, T. Gebel, L. Rebohle, W. Skorupa, Hydrogen plasma treatment of lightemitting materials fabricated on basis of implanted $\mathrm{SiO}_{2}$ with nanocrystalline inclusions, In: Hydrogen Materials Science and Chemistry of Carbon Nanomaterials, eds. D.V. Schur et al. IHSE, Kiev, 2007, p. 1050-1051.

94. Yu.Ya. Bekeris, R.B. Benders, R.P. Kalnynya, I.A. Feltyn, Structure changing, evoked by RF annealing of low-temperature $\mathrm{SiO}_{2}$ films // Izv. AN
Latv. SSR. Ser. Fiz.-Tekhn. Nauki N 6, p. 97 (1984) (in Russian).

95. T.P. Ma, M.R. Chin, RF annealing of radiation induced electron traps in MOS structures // Techn. Digest of IEDM, 1978, p. 224.

96. J.E. Shelby, Radiation effects in hydrogenimpregnated vitreous silica // J. Appl. Phys. 50 (5), p. 3702 (1979).

97. J.D. Weeks, J.C. Tully, L.C. Kimmerling, Theory of recombination-enhanced defect reactions in semiconductors // Phys. Rev. B 12 (8), p. 3286 (1975).

98. T. Sugano, Carrier trapping in silicon MOS devices // Acta Polytech. Scand. Electr. Engineer. Ser. N 64, p. 220 (1989).

99. N.M. Johnson, D.K. Beigelsen, M.D. Moyer, Lowtemperature annealing and hydrogenation of defects at the $\mathrm{Si}_{-} \mathrm{SiO}_{2}$ interface // J. Vac. Sci. Technol. 19 (3), p. 390 (1981).

100. E.E. Heller, Hydrogen in crystalline semiconductors, In: Handbook on Semiconductors, ed. by T.S. Moss, v.3, ed. by. S. Mahajain. Elselvier Science B.V., The Netherlands, 1994, p. 1515.

101. Amorphous Semiconductors, ed. by M.H. Brodsky, Topics in Appl. Phys. 36. Springer, Berlin, 1979, p. 419.

102. A.J.R. De Kock, The elimination of vacancy-claster formation in dislocation - free silicon crystals // $\mathrm{J}$. Electrochem. Soc. 118 (11), p. 1851 (1971).

103. H.J. Stein, S.K Hahn, Hydrogen accelerated thermal donor formation in Czochralski silicon // Appl. Phys. Lett. 56 (1), p. 63 (1990).

104. A.R. Brown, M. Claybourn, R. Murray, P.S. Nandhra, R.C. Newman, J.H. Tucker, Enhanced thermal donor formation in silicon exposed to a hydrogen plasma // Semicond. Sci. Technol. 3, p. 591 (1988).

105. Q. Guagang, H. Zonghu, The convergent effect of the annealing temperatures of electron irradiated defects in FZ silicon grown in hydrogen // Solid State Communs 53 (11), p. 975 (1985).

106. R. Singh, S.J. Fonash, A. Rohatyi, P.R. Choudhary, J.A. Gigante, A low-temperature process for annealing extremely shallow As ${ }^{+}$implanted $\mathrm{n}^{+} / \mathrm{p}$ junction in silicon // J. Appl. Phys. 55 (4), p. 867 (1984).

107. E.I. Terukov, B.J. Ber, V.Kh. Kudojarova, V.Ju. Davydov, A.N. Nazarov, Ja.N. Vovk, S. Ashok, Hydrogen-enhanced transformation of electrical and structural properties of thin subsurface ion implanted silicon layer in $\mathrm{SiO}_{2}-\mathrm{Si}$ systems // Solid State Phenomena 69-70, p. 595601 (1999).

108. S.J. Pearton, Hydrogen passivation of $\tilde{\gamma}$-induced point defects in silicon // Phys. status solidi (a) 72 (1), K73 (1982). 
109. R. Singh, S.J. Fonash, A. Rohatyi, Interaction of low-energy implanted atomic hydrogen with slow and fast diffusing metallic impurities in $\mathrm{Si} / /$ Appl. Phys. Lett. 49 (13), p. 800 (1986).

110. J.I. Pankov, R.O. Wance and J.E. Berkeyheiser, Neutralization of acceptors in silicon by atomic hydrogen // Appl. Phys. Lett. 45 (10), p. 1100 (1984).

111. N.M. Jonhson, C. Herring, D.J. Chadi, Interstitial hydrogen and neutralization of shallow-donor impurities in single-crystal silicon // Phys. Rev. Lett. 56 (7), p. 316 (1986).

112. C.G. Van de Walle, P.J.H. Denteneer, Y. Bar-Yam, S.T. Pantelides, Theory of hydrogen diffusion and reactions in crystalline silicon // Phys. Rev. B 39, (15), p. 10791 (1989).

113. H.J. Stein, Vacancies and the chemical trapping of hydrogen in silicon // Phys. Rev. Lett. 43 (14), p. 1030 (1979).

114. C.K. Ony, G.S. Khoo, Model of two intense Si-H infrared stretching bands in FZ-Si grown in hydrogen // J. Phys. C 20 (3), p. 419 (1987).

115. B.N. Mukashev, S.G. Tokmoldin, M.F. Tamendarov, H.A. Abdulin, E.V. Chikhrai, Hydrogen passivation of dopants and radiation defects in ptype Si // Sov. Phys. Semiconductors 22 (6), p. 1020 (1988).

116. B. Tuttle, C.G. Van de Walle, J.B. Adams, Exchange of deeply traped and interstitial hydrogen in silicon // Phys. Rev. B 59, (8), p. 5493 (1999).

117. T.S. Shi, S.N. Sahu, G.S. Oehrlein, A. Hiraki, J.W. Corbett, Models of the hydrogen-related defect-impurity complexes and $\mathrm{Si}-\mathrm{H}$ infrared bands in crystalline silicon // Phys. status solidi (a) 74, (2), p. 329 (1982).

118. G.L. Gutsev, G.S. Myakenkaya, V.V. Frolov, V.B. Glazman, Nature of hydrogen bonding in SiA-center // Phys. status solidi (a) 153 (2), p. 659 (1989).

119. B.N. Mukashev, S.Z. Tokmoldin, M.F. Tamendarov, V.V. Frolov, Hydrogen passivation of vacancy related centers in silicon // Physica B 170, p. 545 (1991).

120. S.B. Zhang, D.J. Chadi, Microscopic structure of hydrogen-shallow-donor complexes in crystalline silicon // Phys. Rev. B 41 (6), p. 3882 (1990).

121. P.J.H. Denteneer, C.G. Van de Walle, S.T. Pantelides, Microscopic structure of the hydrogenphosphorus complexes in crystalline silicon // Phys. Rev. B 41, (6), p. 3885 (1990).

122. P. Deak, L.C. Snyder, M. Heinrich, C.T. Ortiz, J.W. Corbett, Hydrogen complexes and theit vibretions in undoped crystalline silicon // Physica B 170, p. 253 (1991).

123. G.G. DeLeo, Theory of hydrogen-impurity complexes in semiconductors // Physica B 170, p. 295 (1991).
124. V.S. Lysenko, A.N. Nazarov, I.M. Zaritsii, G. Sherfósó, G. Battistig, J. Gyulai, L. Dozsa, RF plasma modification of heaving destroyed ion implanted surface silicon layer // Phys. status solidi (a) 115 (1), p. 75 (1989).

125. A.N. Nazarov, V.S. Lysenko, S.A. Valiev, M.M. Lokshin, A.S. Tkachenko, I.E. Kunitskii, Flash-lamp annealing and RF plasma annealing of $\mathrm{Al}-\mathrm{SiO}_{2}-\mathrm{Si}$ structures // Phys. status solidi (a) 120 (2), p. 447 (1990).

126. V.L. Vinetskii, G.A. Holodar, Radiation Semiconductor Physics. Naukova Dumka, Kiev, 1979, p. 336 (in Russian).

127. A.F. Saunders and G.T. Wright, Interface states in the silicon/silicon oxide system observed by thermally stimulated charge release // Electron. Lett. 6 (7), p. 207 (1970).

128. J. Bourgoin, M. Lannoo, Point Defects in Semiconductors II. Experimental Aspects. Springer, Berlin, 1983.

129. H. Ryssel, I. Ruge, Ion Implantation. Wiley, New York, 1986.

130. M.L.W. Thewalt, In: Excitons. Nauka, Moscow, 1985, p. 284 (in Russian).

131. M.Ya. Valakh, V.S. Lysenko, A.N. Nazarov, G.Yu. Rudko, N.I. Shakhraychuk, Activation of the implanted impurity and transformation of radiation defects in oxidized silicon under RF plasma treatment // Phys. status solidi (a) 130 (1), p. 45 (1992).

132. A.N. Nazarov, V.M. Pinchuk, V.S. Lysenko, T.V. Yanchuk, Quantum chemical investigations of atomic hydrogen effect on Frenkel pairs annihilation in silicon // Modelling Simul. Mater. Sci. Eng. 4, p. 323 (1996).

133. A.N. Nazarov, V.M. Pinchuk, V.S. Lysenko, T.V. Yanchuk, S. Ashok, Enhanced activation of implanted dopant impurity in hydrogenated cristalline silicon // Phys. Rev. B 58 (7), p. 3522 (1998).

134. A.N. Nazarov, V.M. Pinchuk, T.V. Yanchuk, V.S. Lysenko, Hydrogen enhanced defect reactions in silicon: interstitial atom - vacancy // Mat. Res. Soc. Symp. Proc. 510, p. 367 (1998).

135. A.N. Nazarov, V.M. Pinchuk, T.V. Yanchk, V.S. Lysenko, Ya.N. Vovk, S. Rangan, S. Ashok, V. Kudoyarova, E.I. Terukov, Hydrogen effect on enhancement of defect reactions in semiconductors: example for silicon and vacancy defects // Intern. J. Hydrogen Energy 26, p. 521-526 (2001).

136. S. Kar, P .Zaumseil, S. Ashok, An experimental study of ion beam and ECR hydrogenation of selfion implantation damage in silicon by admittance spectroscopy and x-ray triple crystal diffractometry // Solid State Phenomena 57-58, p. 483 (1997).

137. A.M. Grehov, V.M. Gun'ko, G.M. Klapchenko, Yu.P. Tsjaschenko, Local structural relaxation of hydrogenated vacancy in silicon // Sov. Phys. Solid State 27 (1), p. 285 (1985). 
138. B. Hourahine, R. Jones, S. Oberg, R.C. Newman, P.R. Briddon, E. Roduner, Hydrogen molecules in silicon located at interstitial sites and trapped in voids // Phys. Rev. B 57 (20), p. R12666 (1998).

139. D.J. Chadi, C.H. Park, Electronic properties of hydrogen-derived complexes in silicon // Phys. Rev. B 52 (12), p. 8877 (1995).

140. D. Beeman, R. Tsu, M.F. Thorpe, Structural information from the Raman spectrum of amorphous silicon // Phys. Rev. B 32 (2), p. 874 (1985).

141. S.V. Koveshnikov, S.V. Nosenko, A.M. Surma, Modification of the properties of $\mathrm{Si}$ crystals exposed to atomic hydrogen at high temperatures // Solid State Phenomena 19, p. 165 (1991).

142. V.V. Aristov, S.V. Koveshnikov, S.V. Nosenko, E.B. Yakimov, A.M. Surma, Some aspects of third generation creation of the power silicon switching devices, ruled by nonplanar MOS structure // Mikroelektronika 24 (3), p. 198 (1995) (in Russian).

143. V.S. Lysenko, P.S. Kopev, A.N. Nazarov, G.A. Naumovets, V.B. Popov, A.S. Tkachenko, A.M. Vasiliev and V.M. Ustinov, Thermal reactivation of nonradiative recombination centers in hydrogenated $\mathrm{Al}_{\mathrm{x}} \mathrm{Ga}_{1-\mathrm{x}} \mathrm{As}: \mathrm{Si} / /$ Phys. status solidi (a) 139 (2), p. 541 (1993). 